\title{
Beyond burdens and climate refugees: a stocktake of international responsibility-sharing and South Pacific climate-induced migration
}

\author{
By \\ Daisy Aroha McElwain
}

\begin{abstract}
A thesis
submitted to the Victoria University of Wellington in fulfilment of the requirements of the degree of Master of International Relations
\end{abstract}

Victoria University of Wellington

(2020) 
Beyond burdens and climate refugees: a stocktake of international responsibility-sharing and South Pacific climate-induced migration

Daisy McElwain

300363544

\begin{abstract}
This paper provides a 'stocktake' of common responsibility-sharing principles and goals in international agreements on climate change and refugees/migration to date and investigates how these principles might inform an Oceania agreement to deal with the emerging issue of South Pacific climate-induced migration. Where international agreements on climate change and refugees/migration overlap I identify a set of responsibility-sharing principles and goals and investigate their compatibility with the needs and demands of Pacific communities facing the prospect of climate-induced displacement. In this paper, I tap into ongoing political and academic debates concerning if and how we ought to differentiate states' environmental responsibilities. I ask whose responsibility is it to address climate-induced migration? And what exactly are they responsible for? I find that international agreements on climate change and refugees/migration sufficiently overlap with the needs of Pacific communities to provide us with five common responsibility-sharing principles and goals that are potentially useful in the South Pacific climate migration context: the ability to pay principle, polluter pays principle, prevention, emissions reduction and (funding) adaptation. Notwithstanding responsibility-sharing's negotiation difficulties, these responsibility-sharing principles have significant congruence with Pacific communities' needs and demands, and thus provide us with a valuable starting point for an Oceania agreement on climate-induced migration that is informed first and foremost by the needs of those who may have to leave their homes.
\end{abstract}


Beyond burdens and climate refugees: a stocktake of international responsibility-sharing and South Pacific climate-induced migration

Daisy McElwain

300363544

\section{Acknowledgments}

This thesis is dedicated to the Yazidi women of Serres Refugee Camp.

I would like to thank my supervisor Kate McMillan for her support, even via Zoom in extraordinary circumstances. I would also like to thank Kirsty Burnett, and Carra Hamon for her unwavering support of my mahi both in and outside the workplace.

As always credit is due to my beautiful parents Ross and Suzanne for their love, endless support of my passions and for always taking my phone calls whether they be from Greece or ten minutes down the road. To my annoying brother Levi for all the lockdown yoga sessions and superhero movies. To Sian for the weekly dinners and cups of tea. To Abigail for the sauna sessions and reluctant hugs. To all the amazing wāhine toa (and men) who I'm blessed to call my friends. To Annabel, Iyla, Julia, Gordo, Mary and Cam. To the Ohiro fam for their sisterhood. And last but not least to Pablo, for being my number one fan and the highlight of every long thesis-filled day.

'We are here to remind others, industrialized nations, leaders, major industries, that the earth has always been alive - that the land has eyes. It remembers. It will continue to remember. Long after we leave it.' - Kathy Jetñil-Kijiner 
Beyond burdens and climate refugees: a stocktake of international responsibility-sharing and South Pacific climate-induced migration

Daisy McElwain 300363544

\section{Contents}

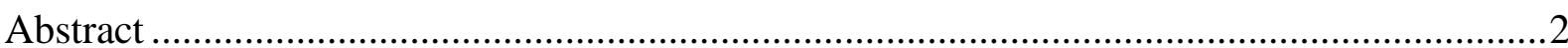

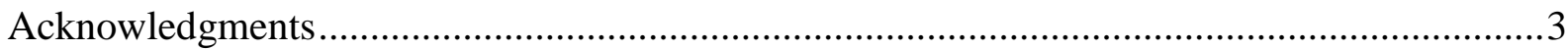

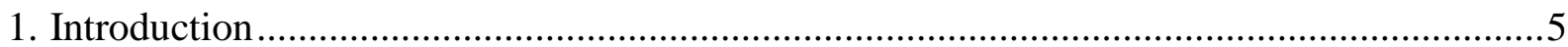

1.1 South Pacific climate-induced migration: a summary ............................................6

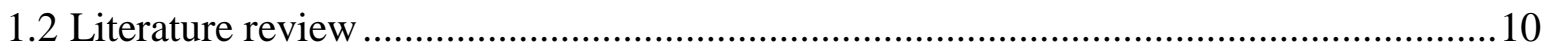

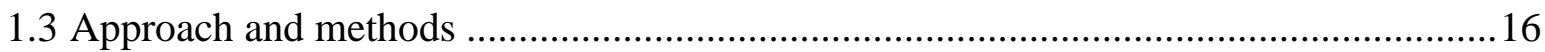

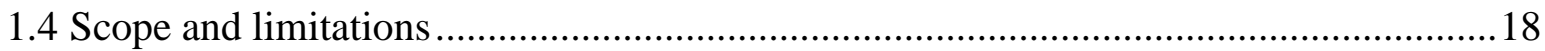

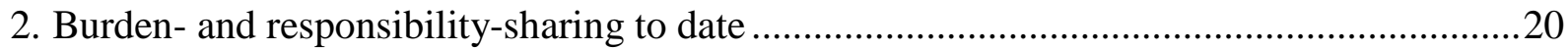

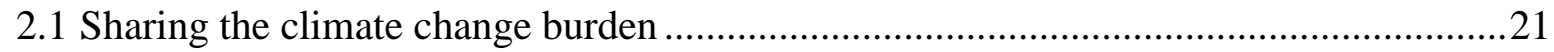

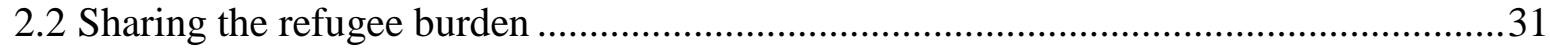

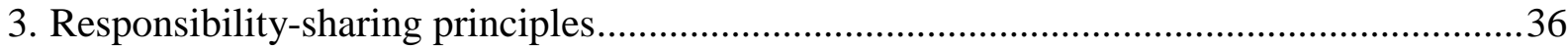

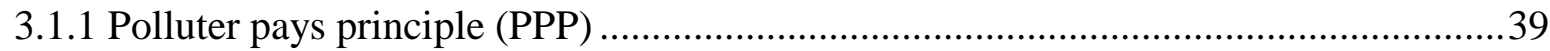

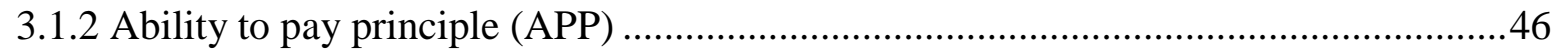

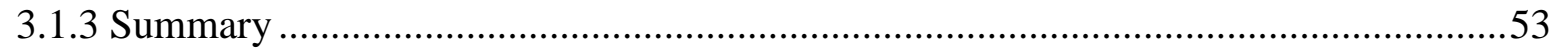

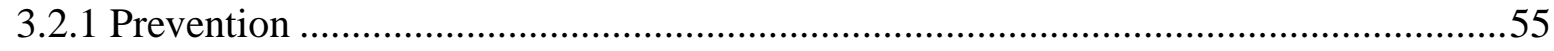

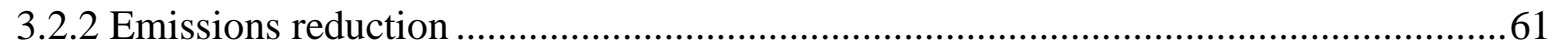

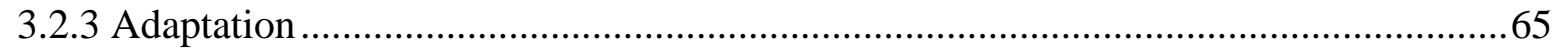

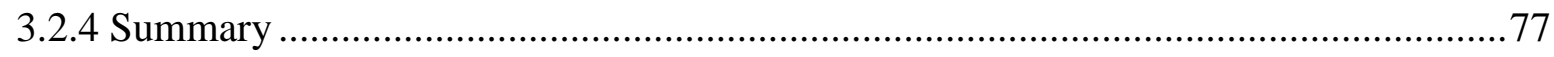

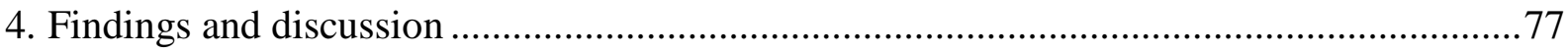

Diagram 1: overlap between international responsibility-sharing agreements and the needs and

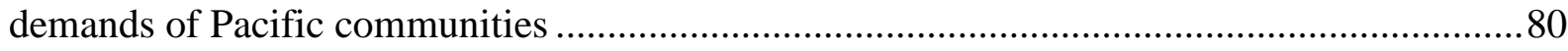

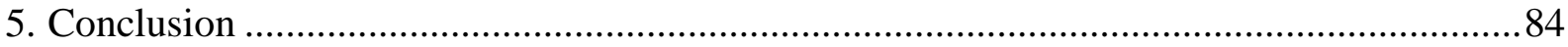




\section{Beyond burdens and climate refugees: a stocktake of international responsibility-sharing and South Pacific climate-induced migration}

Daisy McElwain

300363544

\section{Introduction}

This paper provides a 'stocktake' of common responsibility-sharing principles and goals in international agreements on climate change and refugees/migration to date and investigates how these principles might inform an Oceania agreement to deal with the emerging issue of South Pacific climate-induced migration. Looking at how responsibility-sharing principles have evolved to deal, separately, with climate change and refugees/migration begs the question: what happens when you combine the two issues? Climate-induced migration is an emerging global issue that is politically complex, emotive and increasingly demanding international political attention and action. In particular, in the South Pacific region climatevulnerable Pacific Small Island Developing States face the prospect of cross-border climateinduced displacement. This paper asks: where international responsibility-sharing agreements on climate change and refugees/migration overlap, can we identify a set of common responsibility-sharing principles and goals that might inform an Oceania agreement on climate-induced migration? And importantly, to what extent are these common principles and goals compatible with the needs and demands of Pacific communities facing the prospect of climate-induced displacement? Put simply, how do these responsibility-sharing principles work (or not) in the context of South Pacific climate-induced migration? I find that international agreements on climate change and refugees/migration sufficiently overlap with the needs of Pacific communities to provide us with five common responsibility-sharing principles and goals that might inform a regional Oceania agreement on climate migration; the ability to pay principle, polluter pays principle, prevention, emissions reduction and (funding) adaptation. Importantly, I argue that notwithstanding responsibility-sharing's negotiation difficulties these responsibility-sharing principles and goals have significant congruence with the needs and demands of Pacific communities facing the possibility of climate-induced displacement and thus provide us with a valuable starting point for an Oceania agreement on climate migration that is informed first and foremost by the needs of 
Beyond burdens and climate refugees: a stocktake of international responsibility-sharing and South Pacific climate-induced migration

Daisy McElwain

300363544

those who may have to leave their homes. In this paper, I ask whose responsibility is it to address climate-induced migration? And what exactly are they responsible for?

\subsection{South Pacific climate-induced migration: a summary}

Climate-induced migration is an extremely complex emerging phenomenon with significant implications for international relations. The South Pacific region is unique in that it faces the possibility of cross-border climate-induced migration, while the majority of global climaterelated displacement is internal (Migration Data Portal, 2020). The region's low-lying atoll Pacific Small Island Developing States are disproportionately vulnerable to climate change's adverse impacts. Despite sea-level rise being the focus of dominant sensationalised political, academic and media discourses that perpetuate crisis narratives about 'sinking islands' (see Farbotko, 2010a), rising sea levels is in fact just the tip of the iceberg. Low-lying Pacific Island States are experiencing a multitude of climate change impacts including increased frequency and intensity of extreme weather events such as storm surges, cyclones and prolonged drought, as well as water contamination, ocean acidification and coral bleaching.

These factors are significantly impacting Pacific communities' daily lives and livelihoods. For example, ocean acidification and coral bleaching are resulting in changing fisheries stock upon which Pacific Island States are economically reliant for both employment and food. In addition to driving unemployment, climate change is also resulting in reduced availability and quality of potable water, increased pressure on natural resources, infant mortality and disease, relocation of farm crops and damage to infrastructure. We must also recognise the 


\section{Beyond burdens and climate refugees: a stocktake of international responsibility-sharing and South Pacific climate-induced migration}

Daisy McElwain

300363544

spiritual impact of witnessing one's ancestral home being eroded away and the associated anxieties about loss of culture and identity. ${ }^{1}$

Climate change is not an isolated driver of migration. Rather, climate change can be understood as a 'threat multiplier' (Farbotko, 2018b, p. 248) that interacts with and exacerbates other migration drivers and pre-existing socio-economic issues. All humans are currently experiencing climate change, but not all humans are being forced to leave their homes because of it. This is because climate-vulnerable countries such as Pacific Island States are typically already dealing with significant social, economic, environmental and infrastructure issues, from food and water insecurity to political instability, that render them disproportionately vulnerable to climate change. These pre-existing socio-economic issues are a key ingredient of climate-induced migration. In the words of McAdam and Loughry, climate change can 'trigger a tipping point that would not have been reached in its absence' (McAdam \& Loughry, 2009) by exacerbating a countries' already existing issues and vulnerabilities. This is echoed by Farbotko, who observes that climate change and mobility are "part of a web of vectors which can operate in different directions depending on... the people, place and power relations in question' (Farbotko \& Lazrus, 2012a, p. 384).

Due to its transnational nature, South Pacific climate-induced migration poses a challenge to existing legal mechanisms and international cooperation on forced migration. These existing mechanisms are designed to protect and manage refugees fleeing persecution and are therefore ill-equipped to deal with the complex phenomenon of climate-induced migration. There is a 'protection gap' (Lieberman, 2015) for climate-displaced people under current international refugee law. Despite the highly emotive plight of Pacific 'climate refugees' capturing the imagination of Western news outlets (Høeg \& Tulloch, 2019), these same

\footnotetext{
${ }^{1}$ See Farbotko's work on the concept of solastalgia; the erosion of place-based identities, that helps us to understand the loss and homesickness felt by Pacific communities who are witnessing the environmental degradation of their homes (Farbotko et al., 2016).
} 

Beyond burdens and climate refugees: a stocktake of international responsibility-sharing and
South Pacific climate-induced migration

Daisy McElwain

300363544

'climate refugees' are not guaranteed asylum under the 1951 United Nations (UN)

Convention Relating to the Status of Refugees. Under the Convention's 'nexus' requirement, in order to be considered a refugee one must be fleeing persecution on grounds of race, religion, nationality, membership to a particular social group or political opinion. Therefore, without fear of persecution climate-displaced people are not considered refugees and subsequently not guaranteed asylum. Furthermore, not only is climate migration a legal grey area it is also an awkward political issue that raises uncomfortable questions regarding the differentiation of state responsibilities at the international negotiation table. As such, in lieu of targeted preventative action, the international community has largely treated climateinduced migration as a political hot potato. In addition to the trauma of being forced to leave their ancestral homes, climate-displaced people must also navigate this legal limbo and void of political attention.

South Pacific climate-induced migration is further complicated by ambiguities in pinpointing causation, the wide spectrum of climate (im)mobility decisions and community- and government-level resistance to climate migration. Firstly, let us consider causation. Because climate change exacerbates pre-existing socio-economic issues and interacts with other migration drivers, it is difficult to establish clear causation when it comes to climate migration. This means we cannot simply say that someone is migrating because of climate change. In fact, climate-displaced people are on the move because of a complex web of intersecting factors for which climate change can act as a 'tipping point'. This difficulty in establishing causation has legal and political implications for asylum and climate liability.

Climate migration includes a wide spectrum of climate (im)mobilities, from everyday migration to forced displacement and voluntary immobility. Climate migration must be understood in the context of Pacific peoples' long history of migration, and contemporary economic and social mobility that is the norm for Pacific communities. Indeed, for Tuvaluans, remittances and seasonal work in New Zealand (NZ) are a part of daily life (Farbotko \& Lazrus, 2012, Shen \& Gemenne, 2011). At the other end of the spectrum, in 


\section{Beyond burdens and climate refugees: a stocktake of international responsibility-sharing and South Pacific climate-induced migration}

Daisy McElwain 300363544

response to the prospect of climate migration a minority of indigenous Pacific communities are opting for voluntary immobility where they choose to remain on their ancestral land for cultural and spiritual reasons (Farbotko, 2018, Farbotko \& McMichael, 2019). Others still are involuntarily immobile due to financial constraints. As explained by Zickgraf, "not all people have the same capabilities - or desires for that matter - to leave their homelands for "greener pastures"” (Zickgraf, 2019, p. 227). In other words, climate mobility is not a given nor is it exceptional. This necessitates culturally responsive policy that accounts for Pacific communities' everyday mobility and diverse (im)mobility decisions when it comes to climate migration.

An important piece of the climate migration puzzle is the simple fact that Pacific people may not want to leave their homes. Especially in the context of climate-induced migration, being forced to leave your ancestral home because of far-away countries' historical (and continued) degradation of the environment is not an easy pill for Pacific communities to swallow (Uan, 2013). This is evident in significant community- and government-level resistance to climate migration and some Pacific communities' 'wholesale rejection of the "refugee" label' as undignified (McAdam \& Loughry, 2009). This is problematic for silver bullet legal reform solutions that propose facilitating climate migration as adaptation and treating Pacific peoples as 'climate refugees'. Pacific communities' rejection of the 'climate refugee' label can be understood when we consider their demand for dignified migration, and that many Pacific peoples have seen the suffering of asylum seekers being held in detention centers in Nauru, Manus Island and Papua New Guinea under Australia's 'Pacific Solution' policy. Furthermore, climate migration has predictably become a political tug of war in Pacific Island States (Walters, 2019). For example, in Kiribati the current President's election can be in part attributed to his religious denial of climate migration scoring support from conservative voters. 


\section{Beyond burdens and climate refugees: a stocktake of international responsibility-sharing and South Pacific climate-induced migration}

Daisy McElwain 300363544

Climate-induced migration is a source of much debate at the international negotiation table. The fact that those who are (at risk of) being displaced by climate change are typically the least responsible for climate change raises politically contentious questions of state responsibility, climate liability and blame. Put simply, when it comes to climate migration the most vulnerable are the least responsible. Given the anthropogenic nature of climate change, and Pacific Island States' negligible carbon footprint (Burns, 2002, COP23 The Pacific Islands, n.d.), some states are more to blame for climate migration than others. This has led to ongoing political and academic debate on states' responsibilities and obligations vis-à-vis climate migration. If high-emitting developed countries are responsible for Pacific Island States' disproportionate vulnerability to climate-induced displacement, what should they do about it? These contentious debates on how and if we ought to differentiate state responsibilities for climate migration highlight that existing mechanisms for international cooperation on climate change and migration are ill-equipped to address this emerging issue. Thus, climate-induced migration has significant implications for how states cooperate at the international and regional levels to assign state responsibilities and obligations.

\subsection{Literature review}

Let us apply a critical lens to the existing literature on climate-induced migration. Interestingly, the South Pacific region has become the 'litmus test' or 'poster child' for climate change scholarship (Farbotko, 2010a, Farbotko, 2010b). To date the scant academic, media and political attention afforded to South Pacific climate migration has been largely dominated by sensationalised political, media and academic discourses. These discourses perpetuate crisis narratives about inevitably 'sinking islands' and an influx of 'climate 

Beyond burdens and climate refugees: a stocktake of international responsibility-sharing and
South Pacific climate-induced migration

Daisy McElwain

300363544

refugees' from which Northern borders must be protected. In the words of Farbotko, 'those identified as imminent climate refugees are being held up like ventriloquists to present a particular (western) "crisis of nature"' (Farbotko \& Lazrus, 2012b, p. 383). There is a growing body of opposing research that recognises the vital role of Pacific voices, knowledge and experiences in informing effective policy on climate migration (see Farbotko et al., 2016, Farbotko, 2018a, Perumal, 2018). This paper seeks to make a contribution to this growing field. Indeed, fundamental to this paper is the argument that compatibility with the needs and demands of Pacific communities is a crucial determinant of the effectiveness of an Oceania responsibility-sharing agreement on climate migration. While an entire thesis could easily be devoted to critiquing problematic 'climate refugee' discourses, for the sake of providing a brief literature review I will focus on four main critiques. These are the assumption and victimisation of a homogeneous Pacific 'climate refugee', the securitisation of climate migration, solutions-centricity and fatalistic 'sinking island' narratives.

Firstly, the assumption of a homogeneous Pacific 'climate refugee' is inherently problematic. The 'climate refugee' category fails to account for the complex spectrum of climate (im)mobilities, as well as Pacific communities' diverse needs and demands including their rejection of the 'climate refugee' label. By victimising Pacific peoples as needy climate refugees, this narrative denies agency to Pacific communities that are in fact extremely diverse in terms of their geographical, cultural, economic and political contexts and perspectives on climate change (Oakes, 2019). We must acknowledge the agency and incredible strength and diversity of Pacific communities in the face of climate (im)mobility.

In addition to its cultural insensitivity and fundamental inaccuracies, the climate refugee narrative has dangerous policy implications. Climate refugee discourses are dangerous insofar as they inform policy and international agreements that are ill-equipped to address the realities of South Pacific climate-induced migration. According to Perumal, 'the dominant narrative around Pacific Island "climate refugees" and the associated policy analyses and 


\section{Beyond burdens and climate refugees: a stocktake of international responsibility-sharing and South Pacific climate-induced migration}

Daisy McElwain

recommendations that accompany it are often grossly at odds with the perspectives and intentions of the climate-vulnerable island communities themselves... without a fundamental understanding of this complexity, policy discussions for addressing climate-related migration are bound to be locally inappropriate and uninformed' (2018, p.59). As noted by Perumal, the assumption of a homogeneous Pacific 'climate refugee' goes hand-in-hand with the oversimplification of complex local realities and climate (im)mobilities.

When South Pacific climate-induced migration is framed as a simple issue, it is easy to push silver bullet solutions. These solutions fail to account for the needs and demands of Pacific communities. Silver bullet solutions to climate migration in the existing literature range from legal reform of the 1951 Refugee Convention, to artificial islands (Dolla, 2015) and later discussed migration-as-adaptation policies (see 3.2.3). As an example, large-scale reform of the 1951 Convention to enable the legal protection of 'climate refugees' has obvious implementation problems given both Pacific communities' resistance to being treated as refugees and ongoing debate at the international negotiation table on the differentiation of states' environmental obligations. Instead of advocating for an Oceania responsibility-sharing agreement on climate migration as an ideal solution to climate migration, this paper takes a critical stocktake of responsibility-sharing as it has evolved to deal with climate change and migration/refugees and climate change to date. I provide a set of common responsibilitysharing principles and goals that might serve as a valuable starting point for a regional agreement, while inviting further research into other political and legal mechanisms that must compliment regional responsibility-sharing efforts in order to effectively address this emerging issue. Furthermore, I recognise responsibility-sharing's shortcomings, not least its significant negotiation difficulties. 

Beyond burdens and climate refugees: a stocktake of international responsibility-sharing and
South Pacific climate-induced migration

Daisy McElwain

300363544

Scientific projections range from 25 million to 1 billion 'environmental migrants' being displaced globally ${ }^{2}$ by 2050 (UN Economic and Social Commission for Asia and the Pacific, 2014). However, we must treat fatalistic narratives that predict a mass exodus of climate refugees with caution as they run the risk of becoming a self-fulfilling prophecy. In other words, if we treat Pacific Island States as inevitably sinking, instead of high-emitting states taking on responsibilities for prevention, emissions reduction and adaptation finance, it is up to Pacific communities to move. According to Boas et al., we must be wary of 'selfreferencing' scientific and policy discourses that predict a mass migration of climate refugees from the Global South to the Global North and treat climate migration as a 'looming security crisis' (Boas et al., 2019, p. 901). In effect, the net result of 'sinking islands' discourses is the denial of agency to Pacific people who may want to leave their homes. In order to effectively address this emerging issue, there is a growing need for locally informed policy (and academic research) that accounts for the needs and demands of communities that may be displaced, including ethically and politically complex resistance to climate migration. This paper seeks to balance recognising both the agency of Pacific communities at risk of climateinduced displacement who may not want to move, and the reality that a significant number of these people will migrate overseas as their lives are disrupted and homes become increasingly uninhabitable (Boas et al., 2019).

The securitisation of climate-induced migration is another limitation of the existing literature worthy of note. Securitised discourses on climate-induced migration juxtapose vulnerable, needy climate refugees with benevolent, wealthy countries of refuge. These relational framings of climate migration (Farbotko, 2010b) perpetuate the "North-South axis of security' (Ransan-Cooper et al., 2015). There is a tendency in popular policy and academic discourses to use sensationalist language to frame climate-displaced people as a 'security threat' to the borders of wealthy, high-emitting countries (Ransan-Cooper et al.). For

\footnotetext{
${ }^{2}$ These projections include internal and external displacement. Such projections are limited by methodological inconsistencies and a lack of clarity on what constitutes an 'environmental migrant'.
} 


\section{Beyond burdens and climate refugees: a stocktake of international responsibility-sharing and South Pacific climate-induced migration}

Daisy McElwain

300363544

example, NZ's 2018 Defence Report on 'the climate crisis' identifies 'inevitable' climateinduced migration as a key security concern and source of violent conflict for the South Pacific region (New Zealand Government, 2018b). Importantly for this paper, when Pacific communities at risk of climate-induced displacement are being framed as threats to global, regional, national, or sub-national security, they are not being heard as vital informants of effective policy and agreements.

Making space for Pacific voices in climate migration research is essential to ensure that policies and agreements in this area account for the needs and experiences of those who may have to move. Indeed, I consider congruence with Pacific communities' needs and demands to be a vital determinant of the effectiveness of a regional agreement on climate-induced migration. In other words, an Oceania agreement on climate-induced migration that does not account for the needs and on-the-ground realities of indigenous peoples being displaced is neither likely to effectively address the issue, nor worth a thesis.

This view is echoed by growing calls in the climate migration literature for "communityinformed policy' on climate migration at the international, regional and national levels that is informed first and foremost by Pacific peoples who have lived experiences of climate mobility (see Perumal, 2018, Farbotko, 2018). In the words of a ni-Vanuatu policymaker 'community participation at all aspects [of policy] is a must [...] It makes for better policy when you give a voice to communities' (Perumal, 2018, p. 52). Without vital Pacific voices and insights, policies and agreements in this area will be fundamentally unequipped to deal with the needs and on-the-ground realities of those who are at the frontline of climateinduced migration. The harm of locally inappropriate and uninformed migration policy (Perumal, 2018) cannot be overstated nor done justice on paper. When policies and agreements are not designed to address the inherent challenges of, and recognise the lifechanging nature of, being displaced from one's home, displaced people are effectively left in an unimaginably distressing post-transit limbo. This limbo is especially problematic for 


\section{Beyond burdens and climate refugees: a stocktake of international responsibility-sharing and South Pacific climate-induced migration}

displaced women who, much like all aspects of life, face additional gender-specific challenges (McElwain, 2019).

Let us now consider the existential crisis for all theses; where does this paper fit in the existing literature? This paper seeks to challenge dominant 'climate refugee' academic and policy discourses on South Pacific climate-induced migration and make a contribution to the growing opposing research that provides space to Pacific voices as key informants of effective policy. By investigating common responsibility-sharing principles' compatibility with Pacific communities' needs and demands this paper provides us with a valuable starting point for an effective Oceania agreement on climate migration that is informed first and foremost by the needs of those who may be displaced. There is a clear need for research that treats Pacific people not as security threats but as vital informants of locally appropriate policy, acknowledges the complexity of their perspectives on climate (im)mobility and considers innovative approaches to addressing South Pacific climate-induced migration (McElwain, 2020).

This paper provides the first in-depth look at responsibility-sharing's potential to address climate-induced migration in the South Pacific region. To date very little research has looked at international or regional responsibility-sharing as a possible avenue to deal with climate migration, with the notable exceptions of Eckersley (2015) and Kovner (2017). My research is unique in that it identifies a set of common responsibility-sharing principles and goals where international responsibility-sharing agreements on climate change and refugees/migration overlap, and then investigates their usefulness in the context of South Pacific climate migration. Going forward, it is hoped that the findings of this research will equip scholars and policy-makers with a set of responsibility-sharing principles that are relevant to the South Pacific region and bring us a step closer to an effective regional agreement that is attuned to local context and the significant complexities of South Pacific climate migration. 


\section{Beyond burdens and climate refugees: a stocktake of international responsibility-sharing and South Pacific climate-induced migration}

Daisy McElwain

300363544

\subsection{Approach and methods}

This paper takes a qualitative research approach to investigating responsibility-sharing's potential in the context of South Pacific climate-induced migration. My research has three analytical steps; firstly, I conduct comparative analysis of relevant international agreements to identify common responsibility-sharing principles and goals and trace their evolution in the international environmental and refugee/migration regimes. Secondly, I draw on the relevant literature, political statements and media coverage to situate these principles in the contentious academic and political debates that surround responsibility-sharing. Thirdly, I consider how each common principle and goal would 'work' (or not) in the South Pacific climate migration context. This involves critically evaluating each responsibility-sharing principle and goal's compatibility with the needs and demands of Pacific communities at risk of climate-induced displacement and discussing how the principles might be operationalised in practice.

Comparative analysis of international agreements on climate change and refugees/migration enables us to identify a set of common responsibility-sharing principles and goals that have made it past the international negotiation table (albeit often without enforcement mechanisms) and might prove useful in the context of South Pacific climate-induced migration. This paper considers international agreements to be valuable secondary sources that are in effect records of negotiation dynamics and trade-offs, and therefore have much to tell us about how international responsibility-sharing principles and goals have evolved at the negotiation table. Specifically, I compare three international agreements on climate change: the 2015 Paris Agreement; the 1992 UN Framework Convention on Climate Change (UNFCCC); and the 1997 Kyoto Protocol to the UNFCCC, with three agreements on 

Beyond burdens and climate refugees: a stocktake of international responsibility-sharing and
South Pacific climate-induced migration

Daisy McElwain

300363544

refugees/migration: the 2018 Global Compact on Refugees; the 2018 Global Compact for Safe, Orderly and Regular Migration; and the 1951 UN Convention Relating to the Status of Refugees. Based on comparative analysis of these agreements I identify common responsibility-sharing principles and goals where the two regimes overlap, as well as common principles and goals that are specific to either climate change or migration. For example, the ability to pay principle is a common responsibility-sharing principle that can be found in agreements on both climate change and refugees/migration. On the other hand, the polluter pays principle is specific to issues caused by anthropogenic carbon emissions. As such, the polluter pays principle can only be found in climate change agreements and is not present in agreements on refugees/migration. However, the polluter pays principle has value in the climate migration context, therefore I include it in my research as a common responsibility-sharing principle.

My chosen case study of the South Pacific region is unique in that it faces the possibility of cross-border climate-induced migration. South Pacific climate-induced migration is a complex emerging phenomenon with interesting implications for our understandings of international relations and responsibility-sharing cooperation. The region's low-lying atoll Pacific Island States at risk of climate-induced migration, in particular Tuvalu, have captured the imagination of scholars, politicians and media outlets that perpetuate crisis narratives about 'sinking islands' and Pacific 'climate refugees' (Farbotko, 2010b). Pacific Island States including Tuvalu, Kiribati, Vanuatu, Nauru and the Marshall Islands are the focus of this paper's critical analysis of the degree of overlap between common responsibility-sharing principles and goals and Pacific communities' demands vis-àvis climate migration.

For the purpose of critically analysing responsibility-sharing principles' compatibility with the needs of those being displaced, I have drawn on the existing literature to identify some key needs and demands of Pacific communities when it comes to climate migration. Where possible this analysis is informed by Pacific voices and perspectives from primary academic 


\section{Beyond burdens and climate refugees: a stocktake of international responsibility-sharing and South Pacific climate-induced migration}

Daisy McElwain 300363544

and media sources, political statements from Pacific Island leaders and regional fora, and relevant secondary sources and studies in the existing literature. ${ }^{3}$ Pacific communities' key demands and needs analysed in this paper include: three-pronged urgent preventative action (emissions reduction, adaptation and compensation), traditional village culture understandings of justice, dignified migration, voluntary immobility, 'staying and fighting' (McNamara \& Farbotko, 2017) and preservation of cultures, languages, religions and ways of life. It is important to note that Pacific communities' needs and demands are far from universal. Rather, these needs are diverse, context-specific, sometimes conflicting even within communities (Oakes, 2019) and constantly evolving to deal with the complex climate (im)mobility decisions that more and more Pacifics face (Suliman et al., 2019). Therefore, this paper's analysis of the compatibility of responsibility-sharing principles and goals with Pacific communities' needs comes with the caveat that we must recognise that there is a diverse plurality of Pacific perspectives on climate migration.

\subsection{Scope and limitations}

This paper's scope is limited to its case study; the South Pacific region. This means that while my research is valuable for other regions facing the prospect of internal climate-induced displacement, my findings are particularly relevant to the South Pacific region and its unique case of cross-border climate-induced migration. This limits scope but also enables me to devote detailed and nuanced attention to the local contexts, realities and complexities of

\footnotetext{
${ }^{3}$ Initially I intended to use qualitative data from semi-structured interviews with i-Kiribati and Tuvaluan participants however it was not feasible to conduct these interviews during the COVID-19 pandemic.
} 


\section{Beyond burdens and climate refugees: a stocktake of international responsibility-sharing and South Pacific climate-induced migration}

Daisy McElwain

300363544

Pacific Island States and the South Pacific region in its entirety. Furthermore, this paper investigates the potential of common responsibility-sharing principles to inform an Oceania (not South Pacific) agreement on climate migration. In effect, this excludes countries that do not belong to the Oceania region but might have a stake in a wider South Pacific agreement such as Indonesia and the Philippines. Thus, further research is needed into the buy-in politics of climate change and refugee/migration responsibility-sharing from the Indonesian and Filipino perspectives.

Another limitation in terms of scope is that this paper is focused on state responsibilitysharing. For the purpose of critically analysing responsibility-sharing at the international negotiation table to date, states are the primary units of analysis. This is at the expense of considering non-state actors who have vital roles to play in responsibility-sharing and wider political action on climate-induced migration in the South Pacific region; from nongovernmental organisations (NGOs) and regional fora to grassroots movements such as the Pacific Climate Warriors. Because this research is in essence a stocktake, and international responsibility-sharing cooperation has to date taken place on primarily the state level, I focus on state responsibility-sharing. ${ }^{4}$ However, I recognise the need for and invite further research into multi-stakeholder responsibility-sharing in the context of climate migration.

Now I will provide a brief note on terminology. Firstly, I use the term 'climate-induced migration', or 'climate migration' in short, to refer to external cross-border migration where climate change is an exacerbating migration driver. According to Farbotko, climate-induced migration is 'better attuned to the agency and complexity of populations on the move in a warming world' (Farbotko, 2012, p. 833). Indeed, when I use the term climate-induced

\footnotetext{
${ }^{4}$ The 2018 Global Compact on Refugees placed unprecedented emphasis on a 'multi-stakeholder and partnership approach' as part of its framework for more equitable and predictable burden- and responsibility-sharing.
} 
Beyond burdens and climate refugees: a stocktake of international responsibility-sharing and
South Pacific climate-induced migration

Daisy McElwain

300363544

migration I am referring to the wide spectrum of climate (im)moibltiies in the South Pacific region; from everyday economic mobility to voluntary immobility. Secondly, I use the term 'climate-displaced people' as an alternative to the problematic 'climate refugee label'. As such, 'climate-displaced people' can be understood as a placeholder as Pacific communities navigate climate mobility and arrive at new terms that they feel better reflect this emerging reality. It is also important to note ambiguities concerning the correct terminology for climate-displaced people. More specifically, are climate-displaced people migrants or refugees? There is no clear answer to this question. The matter is complicated by difficulties in pinpointing causation as we cannot to point to climate change as an isolated or primary migration driver, as well as diversity in the (in)voluntariness of climate mobility, Pacific communities' rejection of the climate refugee label and the fact that climate-displaced people are not legally considered refugees under the 1951 Refugee Convention's nexus requirement. This paper leaves room for further research into this grey area, and for now uses the placeholder 'climate-displaced people'.

\section{Burden- and responsibility-sharing to date}

In this section I provide an overview of key developments in the evolution of responsibilitysharing in the international climate change and refugee/migration regimes respectively. The evolution (or rather watering-down) of states' environmental and refugee-related responsibilities to date tells us much about the negotiation politics and ongoing academic debates associated with responsibility-sharing. In particular, the highly contentious question of how and if we ought to differentiate between developed and developing countries' responsibilities continues to play a key role in the negotiation of international agreements on both climate change and refugees/migration. Key developments outlined in this section 
Beyond burdens and climate refugees: a stocktake of international responsibility-sharing and South Pacific climate-induced migration

include the 2015 shift from the Kyoto Protocol's 'Common but Differentiated

Responsibilities and Respective Capabilities' principle to self-differentiation of states' climate change responsibilities under the Paris Agreement. I also discuss the resurgence of political interest in refugee responsibility-sharing with the 2016 New York Declaration, and the resulting 2018 Global Compact on Refugees.

\subsection{Sharing the climate change burden}

Environmental burden- and responsibility-sharing between countries has evolved with the international community's efforts to deal with climate change. Indeed, the climate change burden-sharing regime can be understood as a complex balancing act that emerged as countries sought to address anthropogenic climate change while keeping everyone (developed and developing) at the negotiating table. The notion of differential treatment for developing countries has its origins in post-World War I international cooperation. Calls for developed countries to 'take the lead' (UNFCCC, art. 3(1)) or shoulder greater obligations can be traced back to as early as the 1919 Versailles Treaty (Williams \& Montes, 2016). The Treaty's Part XIII founded the International Labor Organisation and provided a systematic rationale for differential obligations in recognition of countries' 'difference of climate, habits and customs of economic opportunity and industrial tradition' (Versailles Treaty, art. 427). Later, countries' obligations to contribute to the UN's core budget were differentiated through 'capacity to pay' assessed financing (UN Charter, 1945, art. 17), (Williams \& Montes, 2016). Williams and Montes also point to developing countries' push for systematic differential treatment in the late 1960s and the resulting agreement of the aid target of $0.7 \%$ of Gross National Income of developed countries. This laid the foundations for the contemporary international sustainable development regime and the now institutionalised 
Beyond burdens and climate refugees: a stocktake of international responsibility-sharing and South Pacific climate-induced migration

Daisy McElwain

300363544

North-South development aid flows. Thus, the need for equitable differentiation of responsibilities has long been recognised (and debated). Today, the concept of equitably differentiated responsibilities is enshrined in 'Common but Differentiated Responsibilities and Respective Capabilities and Respective Capabilities' (CBDR-RC); a central (albeit now significantly watered-down) principle of environmental cooperation.

CBDR-RC is widely recognised as a cornerstone of the contemporary international climate change burden-sharing regime. The principle seeks to equitably and fairly differentiate states' environmental responsibilities. In effect, under CBDR-RC high-emitting developed countries have greater responsibility to address climate change. The principle was formalised into international law in the UN Framework Convention on Climate Change at the 1992 Rio Earth Summit. CBDR-RC's emergence at the Summit is widely understood as a compromise between, or solution to tensions between, developed and developing countries. The Rio Declaration states (annex 1, principle 7):

In view of the different contributions to global environmental degradation, States have common but differentiated responsibilities. The developed countries acknowledge the responsibility that they bear in the international pursuit of sustainable development in view of the pressures their societies place on the global environment and of the technologies and financial resources they command.

The principle recognises firstly the anthropogenic nature of climate change, and secondly that those who contributed to climate change the least are the most vulnerable to its adverse impacts. For example, low-lying atoll Pacific Island States are uniquely susceptible to climate change-related displacement despite their minimal contributions to global greenhouse gas emissions (Burns, 2002), (COP23 The Pacific Islands, n.d.). In the words of former Kiribati President Anote Tong, 'there is no escaping the deep injustice of the fact that, despite our negligible contributions to greenhouse gas emissions, we are on the frontline of climate 

Beyond burdens and climate refugees: a stocktake of international responsibility-sharing and
South Pacific climate-induced migration

Daisy McElwain 300363544

change consequences... We are being told that we may have to abandon our islands, the places where our ancestors have been buried, where our children have a home' (Tong, 2018). This begs the highly contentious question that CBDR-RC sought to answer: if developing countries are disproportionately vulnerable to change, are high-emitting developed countries more responsible?

The 1997 Kyoto Protocol to the UN Framework Convention on Climate Change (UNFCCC) strengthened and codified CBDR-RC. The Protocol enshrined explicit criteria for the differentiation of countries' climate change obligations and upheld the UNFCCC's Annex classifications. Under the UNFCCC, CBDR-RC differentiates countries' responsibilities for climate change according to two criteria; their historical contributions to the phenomenon (via greenhouse gas emissions), and their capacity to address its adverse impacts (technological and financial capabilities). Importantly, states are classed as either Annex I or non-Annex I parties. Annex I parties include industrialised countries that were Organisation for Economic Co-operation and Development (OECD) members in 1992 and countries with economies in transition (EIT parties). Non-Annex I parties are mostly developing countries, including climate-vulnerable countries. Under the Kyoto Protocol, Annex I countries have greater obligations for mitigation or emissions reduction and their greenhouse gas emissions are legally bound, while non-Annex I countries are effectively exempted from mitigation obligations. Furthermore, Annex II parties (Annex I parties excluding EIT parties) must fund developing countries' emissions reduction efforts and climate change adaptation programmes through the UNFCCC's Financial Mechanism (UNFCCC, art. 11) and its operating entity the Green Climate Fund. In addition, Annex II countries are responsible for ensuring the transfer of environmentally friendly technologies to developing countries and EIT parties.

For high-emitting developed countries such as the United States (U.S), CBDR-RC's differential treatment enforces a double standard where developed countries must reduce their own emissions while funding developing countries' emissions reductions and adaptation 

Beyond burdens and climate refugees: a stocktake of international responsibility-sharing and
South Pacific climate-induced migration

Daisy McElwain

300363544

programmes. For developing countries, CBDR-RC recognises their 'right to emit' and 'atmospheric rights' (Zenghelis \& Averchenkova, 2014). This raises complicated questions; namely, is it developed countries' 'turn' to emit carbon in order to develop? Or do they have an obligation to develop sustainably? (See Rajamani, 2012). According to Indian Prime Minister Narendra Modi 'climate justice demands that, with the little carbon space we still have, developing countries should have enough room to grow' (Modi, COP21 Plenary, Paris, November 30 2015).

CBDR-RC remains a significant point of contention in the negotiation of international climate change agreements. This can be seen most recently in the negotiation of the Paris Agreement and U.S President Donald Trump's subsequent pull-out policy. While being forced to leave their ancestral homes because of others' carbon emissions is a tough pill for Pacific communities to swallow, similarly CBDR-RC is a tough sell domestically for highemitting developed countries. This is perhaps best summed up by President Trump's tweets regarding the Paris Agreement, for example, 'American taxpayers - and American workers shouldn't pay to clean up others countries' pollution' (@realDonaldTrump, December 5, 2018). He also wrote 'people do not want to pay large sums of money, much [less] to third world countries (that are questionably run), in order to maybe protect the environment' (December 9, 2018). According to CBDR-RC, developing countries must take the lead in reducing greenhouse gas emissions and fund developing countries' climate change adaptation in order to enable developing countries' sustainable economic growth. This becomes problematic in the context of emerging economies and the contemporary U.S-China ‘trade war' (@realDonaldTrump, September 5, 2019).CBDR-RC triggers Western hysteria regarding the economic growth of emerging Asian economies such as India and China and the threat they pose to U.S hegemony and the extant unipolar world order. ${ }^{5}$ China's

\footnotetext{
${ }^{5}$ In July 2020 FBI Director Christopher Wray described the Chinese government as the 'greatest longterm threat' to the U.S that is 'engaged in a whole-of-state effort to become the world's only superpower by any means necessary'. In January former U.S national security advisor James Jones
} 

Beyond burdens and climate refugees: a stocktake of international responsibility-sharing and
South Pacific climate-induced migration

Daisy McElwain

300363544

classification as non-Annex I and its resulting exemption from emissions reduction obligations under the Kyoto Protocol is unpalatable for the U.S who perceives China as a growing economic and strategic threat. In sum, responsibility-sharing is 'a political nonstarter for developed countries' (Mayer, 2016, p. 248).

2015 saw a significant shift in how the international community determines countries' responsibilities for climate change. More specifically, we shifted from the Kyoto Protocol's equitable differentiation of responsibilities under CBDR-RC to the 2015 Paris Agreement's self-differentiation of responsibilities through its Nationally Determined Contributions (NDC) mechanism. The Paris Agreement does not refer to Annex I, non-Annex I or any specific country groups. Instead, it effectively abandons CBDR-RC's equitable differentiation of responsibilities in favour of universality. The Agreement imposes universal soft and hard obligations as well as normatively weak 'non-obligations' (Rajamani, 2016) on all parties, while expecting developed country parties to 'continue taking the lead' in emissions reductions (art. 4(4)). The NDC mechanism's creation at the 2013 Conference of the Parties (COP19) in Warsaw was a significant breakthrough in balancing the demands of developed and developing countries. Specifically, using the term 'contributions' rather than 'commitments' accommodated the Like Minded-Group of Developing Countries' demand for no binding commitments for non-Annex I countries as well as the U.S's desire to avoid new commitments that require Senate ratification (Obergassel et al., 2015). Under the NDC mechanism states must determine their own nationally determined contribution for emissions reduction and adaptation and provide transparent NDC communications every five years. Each successive NDC must progress beyond the previous one and reflect parties' 'highest possible ambition' in light of CBDR-RC and their national circumstances.

claimed China is 'strategically intent on replacing the United States as the most dominant culture in the world' (see BBC News, 2020, (Ng, 2020). 

Beyond burdens and climate refugees: a stocktake of international responsibility-sharing and
South Pacific climate-induced migration

Daisy McElwain

300363544

Voight and Ferreira argue that in lieu of the Kyoto Protocol's CBDR-RC criteria and annex classifications, the Paris Agreement's 'highest possible ambition' principle implies a due diligence standard where high-emitting developed countries should ensure that their NDCs are consistent with their domestic circumstances and capabilities (Voigt \& Ferreira, 2016). However, despite this watered-down 'implied standard' there is no explicit criteria for equitable differentiation of responsibilities. Ultimately, states are free to determine their own emissions reduction and adaptation responsibilities (and whether they are equitable or not) within the domestic and international restraints on climate policy. This opens the door to theoretical debate on what constraints there are on states' climate policies, and the likelihood that states will voluntarily take on ambitious or equitable emissions targets.

Some scholars have applauded the Paris Agreement's NDC mechanism as introducing a 'new logic of domestically-driven climate policies' (Urpelainen \& Van de Graaf, 2018, p. 839) that 'embeds country pledges in an international system of climate accountability' (Falkner, 2016, p. 1107). According to this bottom-up logic, developed countries' environmentally conscious electorates and their desire to maintain international normative legitimacy will incentivise them to voluntarily choose ambitious NDC targets. In other words, developed countries will voluntarily take on equitable (and thus greater) emissions reductions targets that are consistent with their capabilities and historical greenhouse gas emissions. Clémençon sees the Agreement as 'an aspirational global accord that will trigger and legitimize more climate action around the world' by mobilising climate activists to influence their governments' climate policies (Clémençon, 2016, p. 3). This view makes the liberal assumption that environmentally concerned citizens have both the desire and capacity to influence their government to voluntarily take on equitable emissions targets. According to Moravcsik, 'representative institutions and practices constitute the critical "transmission belt" by which the preferences and social power of individuals and groups are translated into state policy' (Moravcsik, 1997, p. 518). Furthermore, Voigt and Ferreira argue that we can rely on a 

Beyond burdens and climate refugees: a stocktake of international responsibility-sharing and
South Pacific climate-induced migration

Daisy McElwain

300363544

process of 'international normative pull' and socialised institutional norms to ensure that countries' NDCs reflect their 'highest possible ambition'. This echoes March and Olsen's 'logic of appropriateness' or 'norm-following' where states are socialised into certain behaviours according to their perceived identity or role (March \& Olsen, 2011).

From a realist, rational choice perspective we cannot realistically expect high-emitting developed countries to voluntarily take on greater emissions reduction responsibilities than their developing counterparts. Even if we accept Moravcsik's transmission belt logic, how can we be confident that the demands of environmentally conscious citizens will override the interests of powerful pro-fossil fuel lobbying groups? In addition to the logic of appropriateness we must consider the 'logic of consequences' where countries' rational choices are defined by their desires and capabilities (Schulz, 2016). Under rational costbenefit analysis, will governments sacrifice support from fossil fuel special interest groups that they need for re-election in order to maintain international legitimacy? Trump's pull-out policy on the Paris Agreement suggests no. Obergessel et al. critique the NCD mechanism's bottom-up approach. They observe that its reliance on concerned citizens and reputational risk or 'naming and shaming' has resulted in 'insufficient and non-binding' national contributions that fall significantly short of global greenhouse gas emissions targets. Furthermore, the Paris Agreement 'establishes legally binding obligations of conduct but not obligations of result' (Obergassel et al., 2016, p. 7). In other words, countries must 'prepare, communicate and maintain successive nationally determined contributions' (Paris Agreement, art. 4(2)), but they are not legally obliged to achieve them. Indeed, we have seen substantial gaps between countries' NDC promises and their actual emissions post-2015 (see Climate Action Tracker). For example, the Climate Action Tracker ranked the U.S's NDC targets as 'insufficient', and the major emitter's emissions reduction efforts to date are ranked 

Beyond burdens and climate refugees: a stocktake of international responsibility-sharing and
South Pacific climate-induced migration

Daisy McElwain

300363544

as 'critically insufficient'. ${ }^{6}$ Global progress in emissions reductions (or the lack thereof) since the Paris Agreement suggests that in practice it is not in high-emitting developed countries' rational interest to voluntarily commit to (or stick to) ambitious emissions targets that reflect their historical responsibility and current capabilities. Therefore, the Paris Agreement's shift away from CBDR-RC was a significant development, and indeed a step backwards, in the evolution of climate change responsibility-sharing.

Is CBDR-RC (and the aspirations for equitable burden-sharing that it represents) now obsolete? Is the principle out-of-date in the post-Paris Agreement world of universal obligations, emerging economies and fiercely defended national sovereignty? CBDR-RC is rooted in aspirational ideals of equity and fairness that can be a tough sell for high-emitting developed countries domestically. The principle has long been a significant point of contention along developed-developing fault-lines in international negotiations of climate change agreements. Indeed, in the Paris negotiations we saw that in today's world of politically fashionable universal obligations, CBDR-RC struggles to make it past the international negotiation table without being significantly watered-down. The UNFCCC's Annex classifications have been criticised as outdated in the contemporary global economic context of emerging economies. Tensions concerning the fairness of the developed-versusdeveloping dichotomy is a source of contentious debate at the international negotiation table that seriously compromises CBDR-RC's efficacy and domestic sell-ability (Boyte, 2010). For example, at the COP17 in Durban, Russia proposed that the UNFCCC be amended to recognise 'changes in economic and technological development' since 1992. In the Paris Agreement negotiations developed countries (successfully) campaigned to overcome the Annex classifications' 'static differentiation' or 'firewall' between industrialised and

\footnotetext{
${ }^{6}$ The online Climate Action Tracker compares NDCs and tracks carbon emissions. Their Fair Share rating system evaluates the emissions levels resulting from emissions reductions commitments against effort sharing benchmarks for each country. If all governments were to follow a "critically insufficient" ambition level, global warming would exceed $4^{\circ} \mathrm{C}$.
} 

Beyond burdens and climate refugees: a stocktake of international responsibility-sharing and
South Pacific climate-induced migration

Daisy McElwain

300363544

developing countries (Obergassel et al., 2015, p. 245). They pointed to the rapid economic growth (and increase in emissions) of non-Annex I countries, many of whom have now overtaken the wealth of traditional industrialised countries.

Scholars have critiqued the developed-versus-developing dichotomy that underpins political and academic discussions of burden-sharing. In fact, the Paris negotiations saw increasing diversity in developing countries' negotiation positions and shifting coalitions. The traditional developing countries coalition; the Group of 77 and China, had broken down into the Alliance of Small Island States and Like Minded-Group of Developing Countries who demanded strong emissions reduction action by all large emitters (including newly industrialised countries), and the newly formed Independent Association of Latin America and the Caribbean who called for all countries (including developing) to commit to reducing emissions (Obergassel et al., 2015). Therefore, climate negotiations are not simply a battle between pro-CBDR developing countries and anti-CBDR developed countries. Indeed, Ji and Sha argue that in addition to differentiating between developed and developing countries the international climate change regime must also recognise increasing diversity and subdivision amongst non-Annex I developing countries (Ji \& Sha, 2015). For example, emerging economies such as China are pursuing industrialisation and urbanisation with a resulting rapid rise in recent greenhouse gas emissions, while least developed and small island countries' emissions (and development levels) remain negligible. Boyte goes further, arguing that there are 'inequities inherent in the current system of categorisation' (Boyte, 2010, p. 85). She points to inconsistencies between the 'developing' and 'least developed' categories, significant diversity in developing countries' environmental, economic, political and social contexts, and the categorisation of countries who do not consider themselves to be developing as non-Annex I. This is echoed by Rajamani who critiques the 'broad brush' categorisation of developed versus developing countries as overlooking 'fuzzy margins' and significant differences within the 'developing countries' category (Rajamani, 2012, p. 369). 

Beyond burdens and climate refugees: a stocktake of international responsibility-sharing and
South Pacific climate-induced migration

Daisy McElwain

300363544

Despite CBDR-RC and its Annex classifications going out of fashion politically, the need for equitable differentiation of responsibilities for climate change remains, especially in light of Pacific Island States' disproportionate vulnerability to climate-related displacement. This paper argues that responsibility-sharing has potential in this context, and common responsibility-sharing principles and goals can provide us with a valuable starting point for an Oceania agreement on South Pacific climate-induced migration. Williams and Montes argue that 'CBDR-RC cannot be out of date in a world that remains dominated by clear and prevalent asymmetries, rising inequality amongst countries, differential access to core technology and finance and different conditions of vulnerability' (Williams \& Montes, 2016, p. 114). This was echoed by Prime Minister Modi at the COP21 Plenary in Paris, November 30 2015. He said 'the principles of equity and common but differentiated responsibilities must remain the bedrock of our collective enterprise across all areas - mitigation [emissions reduction], adaptation and means for implementation. Anything else would be morally wrong... It is not just a question of historical responsibility. They [developed countries] also have the most room to make the cuts [in emissions] and make the strongest impact'.

However, we can see in the evolution of the climate change burden-sharing regime to date that responsibility-sharing comes with significant complexity and feasibility constraints. According to Eckersley, the ethical and political trade-offs associated with responsibilitysharing mean that there is a "yawning gap between "the ideal and the real" [that] provides a serious challenge for those seeking justice for climate refugees, who are among the least responsible for, and the most vulnerable to, the impacts of climate change' (Eckersley, 2015, pp. 483-484). 


\section{Beyond burdens and climate refugees: a stocktake of international responsibility-sharing and South Pacific climate-induced migration}

Daisy McElwain 300363544

\subsection{Sharing the refugee burden}

Refugee burden-sharing has seen a recent resurgence in political popularity with the 2016 New York Declaration for Refugees and Migrants and subsequent 2018 Global Compact on Refugees (the Refugee Compact). We can see its origins in the 1951 UN Convention Relating to the Status of Refugees that recognised 'the grant of asylum may place unduly heavy burdens on certain countries' (preamble, recital 4).

As noted by Ineli-Ciger, the Convention did not explicitly deal with burden- or responsibilitysharing nor provide an enforcement mechanism for equitable compensation to over-burdened host countries. This has led to the unequal distribution of asylum-related burdens (the 'burden' of hosting refugees) among UN member states (Ineli-Ciger, 2019). This is echoed by Inder, who argues that in the Convention the burden-sharing principle's form (its confinement to the preamble) and its substance (limited scope and legal effects) laid the foundations for burden-sharing's 'ongoing ambivalence' in international refugee law (Inder, 2017). Indeed, in his closing remarks at the first Global Refugee Forum on 18 December 2019 the UN High Commissioner for Refugees (UNHCR) Filippo Grandi described burdenand responsibility-sharing's application to refugees as 'imperfect since the establishment of the Refugee Convention'.

The 2016 New York Declaration for Refugees and Migrants seemed to show a resurgence in political and academic interest in the long-contested concept of refugee burden-sharing (Inder, 2017). All 193 UN member states committed to more equitable burden- and responsibility-sharing for hosting and supporting refugees. The Declaration also committed states to work towards the 2018 Refugee Compact and Global Compact for Safe, Orderly and Regular Migration (the Migration Compact). The Declaration (para. 68) states: 
Beyond burdens and climate refugees: a stocktake of international responsibility-sharing and South Pacific climate-induced migration

Daisy McElwain

300363544

we commit to a more equitable sharing of the burden and responsibility for hosting and supporting the world's refugees, while taking account of existing contributions and the differing capacities and resources among States.

This renewed political appetite for refugee burden-sharing can be understood in the 2016 context of European Union tensions regarding the (uneven) distribution of hosting responsibilities and the 'Global South' hosting $84 \%$ of the world's refugees (Inder, 2017). Put simply, coastal and conflict-bordering countries were (and continue to be) over-burdened with refugees, creating political appetite to pass the buck or more equitably share the burden of providing asylum. The Declaration and its promised Compacts were celebrated in optimistic academic, political and media discourses as paving the way for a concrete international refugee burden-sharing regime (see UNHCR website). Indeed, in 2017 Inder noted the potential for the burden-sharing norm to 'harden' into more binding commitments over time through the anticipated Compacts. However, the Refugee Compact negotiations encountered the feasibility and buy-in constraints associated with burden-sharing, resulting in the watered-down aspirational Compact with legally non-binding objectives that we have today.

The 2018 Refugee Compact outlines an aspirational responsibility-sharing regime for refugees. The Compact is a legally non-binding agreement that sets out a framework for 'predictable and equitable burden- and responsibility-sharing' amongst UN member states and relevant stakeholders (para. 3). The Compact's introduction states (para. 5): The global compact... seeks to operationalize the principles of burden-and responsibilitysharing to better protect and assist refugees and support host countries and communities.

The Refugee Compact sets out four key objectives: (i) ease pressures on host countries; (ii) enhance refugee self-reliance; (iii) expand access to third country solutions; and (iv) support 

Beyond burdens and climate refugees: a stocktake of international responsibility-sharing and
South Pacific climate-induced migration

Daisy McElwain

300363544

conditions in countries of origin for return in safety and dignity (para. 7). It outlines a programme of action for their achievement, as well as the Comprehensive Refugee Response Framework. The Compact calls on 'the international community as a whole' to strive towards its aspirational objectives, and explicitly describes its framework for more equitable and predictable responsibility-sharing as 'a task for all States, together with relevant stakeholders' (para. 101, emphasis added). Importantly for this paper, the Compact foresees that more predictable and equitable responsibility-sharing for refugees will require complementary action at the global and region- or country-specific levels (para. 15). Thus, the Refugee Compact demonstrates (at least some) political appetite for regional responsibility-sharing to deal with refugee flows. However, according to Ineli-Ciger, the

Refugee Compact falls short of filling the 'normative gap on burden-sharing' in international refugee law left by the 1951 Refugee Convention (Ineli-Ciger, 2019).

The Refugee Compact's primary mechanism for responsibility-sharing, the Global Refugee Forum, falls short of the New York Declaration's promises of equitable burden-sharing. The Compact established the Global Refugee Forum where states are invited every four years to make formal burden-sharing pledges and contributions. Pledges can include financial, material, and technical assistance, review of national policies, laws and practices, resettlement and complementary admission pathways (Türk \& Garlick, 2019). The intention is for the fora to operationalise adequate, stable, and periodic funding and enhance international responsibility-sharing efforts (Aleinikoff et al., 2017). Indeed, UN Secretary General António Guterres said in his opening remarks at the first Global Refugee Forum on 17 December 2019 that the Forum is an opportunity to 'build a more equitable response to refugee crises through a sharing of responsibility' and 'the international community must do far more to shoulder this responsibility together.' Yet the Forum relies on completely voluntary contributions from states and relevant stakeholders. According to Ineli-Ciger, the Refugee Compact 'only plays lip service to burden- and responsibility-sharing by setting up 

Beyond burdens and climate refugees: a stocktake of international responsibility-sharing and
South Pacific climate-induced migration

Daisy McElwain

300363544

an endless loop of conversations and voluntarist pledging conferences' (Ineli-Ciger, 2019, p.131). Without clear criteria or a mechanism for equitably differentiating states' refugee responsibilities, how states share their responsibilities is up to them. In other words, the Refugee Compact does provide a framework for responsibility-sharing, but its equitability or predictability in practice is up to states. The Forum's accountability mechanisms; the online pledges and contributions tracking dashboard and Compact Indicators Framework, do not hold states accountable to standards of equity. Rather, they review states' progress towards their (arguably inadequate) voluntary pledges (Yoon, 2020). Thus, the Global Refugee Forum raises similar questions to the Paris Agreement's NDC mechanism regarding states' (un)willingness to voluntarily take on their fair share of the 'refugee burden'.

The first Global Refugee Forum hosted in Geneva December 2019 saw the Compact's (supposedly equitable) burden-sharing in practice. Mainstream media coverage and the UNHCR applauded the 'billions of dollars and in-kind contributions' pledged at the Forum (Schlein, 2019) and the private sector 'stepping up for refugees' (UNHCR, 2019). The Forum saw financial and non-monetary pledges including increased resettlement quotas and refugee input in policy-making. Financial pledges included approximately $\$ 3$ billion from states, $\$ 250$ million from the private sector and several billions of dollars from development banks. However, these pledges are in fact relatively modest in comparison to the UNHCR's 2020 budget of USD $\$ 8.668$ billion (Sewell, 2019). Egeland observes that the Forum lacked significant financial and hosting pledges from the 'missing middle'; large and emerging economies not taking on adequate hosting or financial responsibilities while developing countries host the majority of the world's refugees (Karasapan, 2020). Furthermore, it remains unclear if states' 'new' financial pledges demonstrate additionality or were merely repackaged from earlier conferences (Yoon, 2020) and existing funds (Karasapan, 2020). The Global Refugee Forum was also criticised for inadequate refugee representation and not enough pledged funding going towards refugee-led initiatives (Sewell, 2019). In sum, the 

Beyond burdens and climate refugees: a stocktake of international responsibility-sharing and
South Pacific climate-induced migration

Daisy McElwain

300363544

Global Refugee Forum's critics see it as a continuation of 'business as usual'. Yoon writes 'the Forum signalled that responsibility-sharing remains ad hoc and refugee-hosting countries will continue shouldering much of the burden' (Yoon, 2020).

Let us now place the Refugee Compact's aspirational framework for responsibility-sharing in the context of climate-induced migration. The Refugee Compact recognises that 'external forced displacement may result from sudden-onset natural disasters and environmental degradation', and states 'may seek support from the international community' to address the complex challenges associated with environmental displacement (para. 12). The Compact further states that 'while not in themselves causes of refugee movements, climate, environmental degradation and natural disasters increasingly interact with the drivers of refugee movements' and calls for early prevention efforts and improved cooperation to address these root causes of migration (para. 8). Türk \& Garlick note that paragraph 8 takes a 'cautious approach' to climate-induced migration (Türk \& Garlick, 2019). Despite climatedisplaced peoples' ongoing legal ambiguity under international refugee law, the scholars argue that the Refugee Compact's aspirational responsibility-sharing framework is a valuable starting point for international efforts to address climate-induced displacement. The scholars see the Compact as 'an important step forward in States' engagement with the questions and needs around displacement in the context of ...the adverse effects of climate change.' Yet they note that 'vision, ambition, and investment by States and other stakeholders will be required to help ensure that its provisions on climate change and disaster displacement can be fully realized' (Türk \& Garlick, 2019, p. 399).

What does the evolution of refugee burden-sharing cooperation in international agreements to date tell us? Its ambiguity under the 1951 Convention, revival with the New York Declaration and subsequent watering-down into the aspirational Refugee Compact framework shows us that 'political reality' is the primary obstacle to binding and enforceable refugee burden-sharing (Ineli-Ciger, 2019). As observed by Ineli-Ciger, 'today very few 
Beyond burdens and climate refugees: a stocktake of international responsibility-sharing and
South Pacific climate-induced migration

Daisy McElwain

300363544

States are willing to be bound by clear pre-determined criteria and share the burden of others hosting large numbers of refugees' (pp. 129-130). Looking at the evolution of both environmental and refugee responsibility-sharing international cooperation to date, we can see the watering-down of responsibility-sharing as it encounters significant feasibility constraints in international negotiations.

\section{Responsibility-sharing principles}

What is clear is that climate-induced migration demands effective cooperation at the international and regional levels. The inherent inequities of anthropogenic climate change and the fact that those who have contributed to it the least; such as Pacific Island States, are bearing the brunt of its adverse impacts, means that states' environmental obligations and responsibilities must recognise this disproportionate vulnerability and be equitably differentiated. The need for equitable responsibility-sharing to address climate-induced migration has two aspects; firstly, being prepared for and addressing the root causes of increased refugee flows is in the rational interest of receiving countries, and secondly, from a normative human rights-based perspective there is a fundamental collective international responsibility to protect and address the needs of climate-displaced people. Dowd and McAdam compare responsibility-sharing in environmental and refugee law and conclude that 'while there are some fundamental differences between responsibility sharing in the two regimes... no single state can resolve the drivers of refugee movement or respond to the protection needs of the world's refugees, just as no single state can mitigate or address the global impacts of climate change. The need for international cooperation and responsibility sharing in both cases is clear... indeed, it is a humanitarian imperative' (Dowd \& McAdam, 2017a, pp. $180 \& 215)$. Sharing state responsibilities for climate-induced migration is no small feat. In addition to the complexities of climate migration, as we have seen 

Beyond burdens and climate refugees: a stocktake of international responsibility-sharing and
South Pacific climate-induced migration

Daisy McElwain

300363544

responsibility-sharing is a long-contested model of cooperation that we can expect to encounter significant buy-in constraints and tensions around differential treatment at the negotiation table. Thus, the proposed Oceania responsibility-sharing agreement to address climate-induced migration in the South Pacific raises interesting questions. Namely, whose responsibility is it to address climate-induced migration? What exactly are states responsible for? Should these responsibilities be shared equitably (and what does equitable differentiation of responsibilities look like anyway)?

This paper sees burden-sharing as fundamentally incompatible with the needs and demands of Pacific communities who are at risk of climate-related displacement. Instead, I look at the potential of responsibility-sharing to address South Pacific climate-induced migration. This shift from burden- to responsibility-sharing has significant conceptual and policy implications (Dowd \& McAdam, 2017a). The notion of a 'refugee burden' to be shared (and shirked) amongst states inherently assumes that hosting, protecting and assisting displaced people has negative consequences for the responsible state. Thus, burden-sharing in the context of climate migration assumes that climate-displaced people are economic, welfare and social burdens for receiving countries. Put simply, burden-sharing is 'loaded to the negative' (Parker, 2008, p. 3). Political framing of refugees and migrants as a burden for states to avoid or reluctantly take on is extremely problematic in light of Pacific communities' key demand for dignified migration. Former i-Kiribati President Tong's 'migration with dignity' policy involved building on existing cross-border labour arrangements, improving domestic educational opportunities and up-skilling i-Kiribati people through vocational programmes. In effect, the idea was to up-skill i-Kiribati people into employable assets for host countries rather than economic or welfare burdens (McNamara, 2015). This means shifting the climate migration narrative from relational framings of the needy South versus the benevolent North (Farbotko, 2010b) to optimistic framing of climate-induced migration as economically beneficial for both sending and receiving countries. 
Beyond burdens and climate refugees: a stocktake of international responsibility-sharing and South Pacific climate-induced migration

Daisy McElwain

300363544

Scholars have also criticised the notion of a 'climate change burden'. Zhang and Shi advocate for 'opportunity sharing' in international climate change cooperation (Zhang \& Shi, 2014). They argue that treating emissions targets as an opportunity for local economic growth rather than an economic burden increases the likelihood of climate action at the negotiation table. Zenghelis and Averchenkova observe that framing emissions reduction obligations as undesirable 'burdens' implies a converse desirable 'right to emit' (Zenghelis \& Averchenkova, 2014). Similarly, we can argue that framing states' refugee hosting responsibilities as undesirable 'burdens' implies a converse desirable right to deny asylum or discourage migration. Thus, a burden-sharing regime for climate-induced migration reduces the degree of ambition at the negotiation table as well as being fundamentally incompatible with Pacific communities' determination to maintain their dignity. I-Kiribati and Tuvaluan peoples' demand for dignified migration ties into two more needs; respect for national sovereignty and determination to preserve their cultures, languages, religions and ways of life. This is explained by a Tuvaluan NGO Manager interviewed by Farbotko:

'we don't want to...relocate to other countries, to burden them, because we have our own culture and we want to maintain that... we have sovereignty, and we want to maintain that.' (Farbotko et al., 2016, p. 540)

We must shift the narrative from states shirking burdens or passing the buck, to equitable sharing of state responsibilities and obligations vis-à-vis climate migration.

\subsection{Who is (more) responsible?}

How and if we should differentiate states' responsibilities and obligations for climate change and refugees/migration has long been contested. This section's comparative analysis highlights two common responsibility-sharing principles that guide who is exempt from 
Beyond burdens and climate refugees: a stocktake of international responsibility-sharing and South Pacific climate-induced migration

Daisy McElwain

300363544

certain obligations and who must 'take the lead' in international responsibility-sharing agreements; the polluter pays principle and ability to pay principle. There is much political and academic debate concerning the differentiation of state responsibilities for climate change and refugees for us to dive into. Should states' responsibilities for climate-induced migration be differentiated on the basis of their historical greenhouse gas emissions (polluter pays principle) or their relative capabilities (ability to pay principle)? Or both, as proposed by the Common but Differentiated Responsibilities principle? We must investigate what equitable and fair responsibility-sharing looks like in the context of South Pacific climateinduced migration. Is differential treatment between developed and developing countries equitable, or unfair and outdated? It depends who you ask. Let us turn to the existing agreements, relevant literature and Pacific perspectives to unpack the polluter pays principle and ability to pay principle.

\subsubsection{Polluter pays principle (PPP)}

The question of who should 'pay' for climate change and its adverse impacts has dominated the negotiation of relevant international responsibility-sharing agreements. In the UN Framework Convention on Climate Change (UNFCCC) and Kyoto Protocol, states' environmental responsibilities are differentiated on the basis of the Common but Differentiated Responsibilities principle that draws on both the polluter pays principle (PPP) and the ability to pay principle (APP). Under the UNFCCC and the Kyoto Protocol developed countries are classed as Annex I parties (and thus assume greater responsibilities 

Beyond burdens and climate refugees: a stocktake of international responsibility-sharing and
South Pacific climate-induced migration

Daisy McElwain 300363544

for emissions reduction and funding adaptation) according to the Common but Differentiated Responsibilities principle's two criteria; their historical greenhouse gas emissions (PPP) and current technological and financial capabilities (APP). Therefore, PPP and APP are not mutually exclusive. For now, I focus on PPP.

The polluter pays principle differentiates states' climate change responsibilities on the basis of their liability for historical greenhouse gas emissions. PPP is a backward-looking principle of remedial responsibility (Kovner, 2017). Simply, according to PPP the polluter should pay for the costs of pollution. PPP first emerged as an economic principle formulated by the OECD in 1972, and has since become a hotly contested principle of environmental cooperation (Eckersley, 2015). Under PPP, industrialised countries that have historically contributed the most carbon emissions are now liable for climate change's adverse impacts and costs that have been externalised onto third parties (Eckersley, 2015). Kovner sees PPP as grounded in outcome responsibility with the distributive aim of 'shift[ing] burdens from the individual who suffers from the outcome to the individual who caused the outcome' (Kovner, 2017, pp. 51-52). Thus, according to PPP, high-emitting developed countries are historically responsible for Pacific Island States' disproportionate vulnerability to climateinduced migration and now they must 'foot the bill' (Caney, 2005, p. 752). At PPP's core is the normative assumption that developed countries have a moral obligation (based on their historical emissions) to take on greater responsibility for the costs of climate change.

Needless to say, blame-laden language such as 'polluter pays' and 'liability' is not explicitly used in international agreements. Instead, PPP's differential treatment on the basis of historical emissions has made it past the international negotiation table as an implied part of the Common but Differentiated Responsibilities principle - at least until 2015. Interestingly, the UNFCCC's foreword uses the strongest language on historical responsibility, recognising that: 

Beyond burdens and climate refugees: a stocktake of international responsibility-sharing and
South Pacific climate-induced migration

Daisy McElwain

300363544

the largest share of historical and current global emissions of greenhouse gases has

originated in developed countries, that per capita emissions in developing countries are still relatively low and that the share of global emissions originating in developing countries will grow to meet their social and development needs

PPP's rise and fall (to date) in the contemporary climate change regime highlights the principle's inherent ethical, legal and political complexities. The UNFCCC and Kyoto Protocol differentiated states' responsibilities on the basis of both their historical emissions and their current ability to pay. As previously discussed, with the Paris Agreement we saw a shift to the ability to pay principle when the Common but Differentiated Responsibilities principle and its Annex classifications were abandoned in favour of self-differentiation of responsibilities under the Nationally Determined Contributions mechanism. Looking backwards to differentiate states' current environmental responsibilities on the basis of their historical contributions to climate change (via greenhouse gas emissions) is a significant step forward in addressing Pacific Island States' disproportionate vulnerability to climate-induced migration justice-wise, but PPP's political feasibility is up for debate.

PPP and its notion of liability for climate change is ethically complex and a tough sell politically. As noted by Ji and Sha, assigning liability and forcing developed countries to commit to long-term emissions targets runs the risk of rendering the negotiation and implementation of environmental responsibility-sharing agreements a 'blame game' where 'insincere over-commitments [are] accepted formally around the negotiating table but never really enforced for fear of excessive costs' (Ji \& Sha, 2015, p. 422). Pickering and Barry critique the notion of a 'climate debt' that wealthy countries owe to poor countries. They argue that although PPP is morally defensible, it is unhelpful for advancing climate justice in international climate negotiations due to its inherently adversarial nature and measurement problems (Pickering \& Barry, 2012). Indeed, Høeg and Tulloch's media analysis finds that 'the non-assumption of responsibility for climate change by the Global North' is enabled by 


\section{Beyond burdens and climate refugees: a stocktake of international responsibility-sharing and South Pacific climate-induced migration}

Daisy McElwain 300363544

'selective amnesia when it comes to the origins of environmental problems or the attribution of any national involvement in their creation' (Høeg \& Tulloch, 2019, pp. 233, 243). Mann observes that 'for elites of the North... the way forward is through the erasure of the record of past wealth-producing emissions and the declaration of an atmospheric blank slate' (Mann, 2018, p. 65). These complexities lead Eckersley to conclude that 'while it is possible to develop a defensible ethical account of historical responsibility it is clear from the history of the climate negotiations that this argument would not provide a politically fruitful basis for advancing the negotiations on... a new agreement or mechanism to manage climate refugees' (Eckersley, 2015, pp. 486-487).

Even if we accept the normative argument that developed countries should be liable for climate change's adverse impacts, how do we accurately measure countries' relative contributions and differentiate their climate change responsibilities on this basis? What about the adverse impacts of climate change that cannot be attributed to a particular polluter, such as climate-induced migration? (Eckersley, 2015). An oft-cited critique of PPP is the idea of 'excusable ignorance' (Pickering \& Barry, 2012). Should countries that were not aware of pollution's harmful impacts be considered liable for those harmful impacts? Some scholars have proposed that states are responsible for their greenhouse gas emissions from the date that they became aware of climate change (see Gardiner, 2011), but there are obvious difficulties in pinpointing an exact moment of national environmental realisation. Indeed, even in the contemporary context of near-global scientific consensus on climate change, the U.S democratically elected President Trump who described climate change as a Chinese hoax. $^{7}$

\footnotetext{
${ }^{7}$ President Trump tweeted on November 72012 'global warming was created by and for the Chinese in order to make U.S. manufacturing non-competitive' and described global warming as a 'very expensive hoax’ on December 72013 (@realDonaldTrump).
} 

Beyond burdens and climate refugees: a stocktake of international responsibility-sharing and
South Pacific climate-induced migration

Daisy McElwain 300363544

Some scholars have pointed to the beneficiary pays principle (BPP) as an alternative to PPP and its associated blame game (Page, 2012 \& Couto, 2018). BPP takes a 'no fault' approach by requiring industrialised countries to 'give up' benefits they have 'unwittingly but unjustly acquired' (Eckersley, 2015, p. 487). This concept of 'guiltless responsibility' is evident in Bolivia's statement at the 2009 Copenhagen Summit. 'Even if the fire was not started on purpose, the industrialised countries, through their inaction, have continued to add fuel to the fire... We are not assigning guilt, merely responsibility. As they say in the US, if you break it, you buy it' (Pickering \& Barry, 2012, p. 673). However, shirking of blame is unacceptable from the perspective of Pacific communities. BPP is incompatible with Tuvaluan and iKiribati people's demand for accountability as well as action from the major greenhouse gas polluters (McNamara \& Farbotko, 2017). While BPP may be more palatable for developed countries, this is because unlike PPP it does not require that developed countries 'own up' to or accept liability for their past emissions.

PPP's notion of climate liability resonates with i-Kiribati traditional village culture understandings of justice. Pacific communities' demand for recognition of past wrongs is explained by i-Kiribati climate change activist Linda Uan.

'In our traditional village culture, we all understand that if somebody does a wrong, they have to reciprocate for their unacceptable behaviour towards an individual or the community as a whole. We are therefore left puzzled and challenged by the fact that the continued abuse of the environment by wealthy nations means we are the ones who have to suffer. Our sense of fair play, of right and wrong, and of justice is being severely tested.' (Uan, 2013)

As explained by Uan, from an i-Kiribati perspective wealthy, industrialised countries who have 'done a wrong' by polluting the environment at the expense of Pacific peoples and communities must now 'reciprocate for their unacceptable behaviour'. Interestingly, this 

Beyond burdens and climate refugees: a stocktake of international responsibility-sharing and
South Pacific climate-induced migration

Daisy McElwain 300363544

demand for recognition of past wrongs comes with a demand for 'reciprocal action' that is proportionate to the 'wrong' that has been done. If we accept that historical carbon emissions are a 'wrong' that must be righted, it can be argued that PPP's fault-based differentiation of responsibilities and the resulting obligation of historical emitters to take on greater environmental responsibilities is a means of enforcing reciprocal action that is proportionate to these historical wrongs. Indeed, in the UNFCCC negotiations the Alliance of Small Island States was PPP's only supporter ${ }^{8}$ (Eckersley, 2015).

Marshallese activist and poet Kathy Jetñil-Kijiner provides us with further insight into the perspective that Pacific communities have been unfairly wronged - and the associated demand for historical emitters to right these wrongs by taking on greater climate change responsibilities. She observes that 'for a greater good' is an unfair reasoning that has historically enabled industrialised countries' degradation of the environment at the expense of Pacific communities, as historical emitters have acted with the conviction that their "need for consumption outweighs the livelihoods of others' (Jetñil-Kijiner, 2016). In this sense, obligating polluters to 'pay' by taking on greater responsibilities for climate-induced migration can be understood as a matter of restoring balance or righting historical wrongs.

Let us consider what PPP means in practical terms for how we differentiate states' responsibilities vis-à-vis climate migration. Do developed countries' historical emissions render them liable for Pacific Island States' disproportionate vulnerability to climate-induced migration today? Does this mean that historical emitters must take on greater responsibility for addressing climate migration? Wall argues that 'the apportionment of blame for refugee flows is neither necessary nor appropriate in the refugee context' (Wall, 2017, p. 226). However, climate-induced migration and its complicated causal relationship with anthropogenic climate change seems to demand some kind of liability on the part of

\footnotetext{
${ }^{8}$ It is important to note that Pacific Island States' support for PPP has been neither consistent nor universal.
} 


\section{Beyond burdens and climate refugees: a stocktake of international responsibility-sharing and South Pacific climate-induced migration}

Daisy McElwain

300363544

developed countries. According to Mayer, PPP's normative assumption that developed countries should take on greater responsibility for the costs of climate change holds up in the context of climate-induced migration. He argues that 'attributing migration to climate change suggests that some are responsible for the sufferings of others, hence that the former owes specific obligations toward the latter' (Mayer, 2016, p. 213).

But how would PPP-based differentiation of climate migration responsibilities work in practice? Attributing blame for climate-induced migration to certain states is far from straightforward. Even attributing migration to climate change is complex, as we cannot point to climate change as an isolated driver of migration. So, who is to blame for climate migration? In the South Pacific, must Pacific Island States' larger, developed neighbours NZ and Australia now 'pay' for the adverse impacts of their historical greenhouse gas emissions? How can we establish clear causation or measure the degree to which their historical emissions have contributed to low-lying Pacific Island States' vulnerability to climateinduced migration? Do NZ and Australia's continued emissions despite government-level recognition of climate-induced migration in the region ${ }^{9}$ constitute a form of neglect that renders them further liable, or is there a cut-off date for liability? Caney summarises these scientific and legal complexities in the application of PPP. He argues that to apply PPP 'we need to be able to specify the harm done and trace it back to the causal actors and where either the nature of the harm is uncertain or unpredictable... or the link between the climate change and the harm is uncertain... then this cannot be done' (Caney, 2010, pp. 206-207). In sum, although PPP has strong moral appeal in the climate migration context, in practice its application raises significant difficulties in terms of pinning down causation and liability.

\footnotetext{
${ }^{9}$ According to the NZ government's 2018 Cabinet Paper on Pacific climate change-related displacement and migration 'over the past decade, New Zealand has recognised the potential for climate migration' (New Zealand Government, 2018a, p. 6). In 2007 the Australian Parliament heard (and did not pass) the Migration (Climate Refugees) Amendment Bill proposing a climate refugee visa category.
} 


\subsubsection{Ability to pay principle (APP)}

Differentiation of states' responsibilities on the basis of their ability to pay (APP) is a common principle of both refugee and climate change responsibility-sharing. In contrast to PPP's differential treatment on the basis of historical liability, APP looks at states' current capabilities. APP is a forward-looking principle that differentiates states' responsibilities on the basis of their relative financial and technological capabilities. According to APP, those with greater capacity to remedy a problem (wealthy, developed countries) should shoulder more of the relevant obligations (Kovner, 2017). Therefore, states' duties and obligations visà-vis climate change and/or refugees increase in line with their wealth (Caney, 2010). In Eckersley's words, APP 'require[s] all states to do what they can within the limits of their respective ability to assist climate refugees, irrespective of their causal contribution to the problem' (Eckersley, 2015, p. 488). Instead of PPP's focus on righting past wrongs, APP assigns responsibilities for addressing an issue on the basis of who can 'get the job done' (Eckersley, 2015, p. 492).

We can see APP in the contemporary refugee/migration responsibility-sharing regime. APP is a key principle of both of the 2018 Compacts; the Refugee Compact and Global Compact for Safe, Orderly and Regular Migration. The Refugee Compact's responsibility-sharing framework is underpinned by recognition of states' differing capacities and resources. The Compact states (para. 1): 

Beyond burdens and climate refugees: a stocktake of international responsibility-sharing and
South Pacific climate-induced migration

Daisy McElwain

300363544

There is an urgent need for more equitable sharing of the burden and responsibility for hosting and supporting the world's refugees, while taking account of ... the differing capacities and resources among States.

In accordance with APP, under the Refugee Compact states' self-determined voluntary contributions will take into account their 'national realities, capacities and levels of development' (para. 4). The Refugee Compact also recognises states' differing contexts and frameworks (para. 50), their absorption capacity, level of development and demographic situation (para. 85). Similarly, the Migration Compact states that its implementation must take into account 'different national realities, capacities, and levels of development, and respecting national policies and priorities' (para. 41). Interestingly, APP is interlinked with the Migration Compact's guiding principle of national sovereignty that explicitly recognises states' 'sovereign right' to determine their own migration policies in accordance with their different national realities and priorities (para. 15). This suggests that in the refugee/migration responsibility-sharing regime, respect for national sovereignty and recognition of differing 'national realities' can go hand-in-hand. Although the 2018 Compacts fall short of specifying exactly what national capacities and realities should be accounted for under APP (i.e. financial or technological), APP-based differentiation of responsibilities has come a long way in the refugee/migration context since the 1951

Convention which did not recognise any kind of difference in states' ability to fulfil their refugee-related obligations.

In the climate change context, states' environmental responsibilities and obligations have long been differentiated on the basis of their ability to pay under the Common but Differentiated Responsibilities principle. As early as the 1992 UN Framework Convention on Climate Change (UNFCCC) we can see the normative 'respective capabilities' principle that corresponds with APP. The Convention's Article 3(1) states: 
Beyond burdens and climate refugees: a stocktake of international responsibility-sharing and South Pacific climate-induced migration

Daisy McElwain

300363544

Parties should protect the climate system... on the basis of equity and in accordance with their common but differentiated responsibilities and respective capabilities. Accordingly, the developed country Parties should take the lead in combating climate change and the adverse effects thereof.

The Convention goes on to impose commitments on all parties with the caveat of accounting for their respective capabilities under the Common but Differentiated Responsibilities principle, as well as national and regional development priorities, objectives and circumstances (art. 4(1)). The Convention's respective capabilities principle explicitly places the onus on developed countries, and even conditions developing countries achieving their commitments on developed countries supporting them to do so. We can see this in Article 4(7):

The extent to which developing country Parties will effectively implement their commitments under the Convention will depend on the effective implementation by developed country Parties of their commitments under the Convention related to financial resources and transfer of technology and will take fully into account that economic and social development and poverty eradication are the first and overriding priorities of the developing country Parties.

Five years later, the Kyoto Protocol strengthened and codified the Common but Differentiated Responsibilities principle, and with it the UNFCCC's 'respective capabilities' principle. Under the Protocol states' environmental responsibilities are differentiated on the basis of their Annex classifications and their 'common but differentiated responsibilities and their specific national and regional development priorities, objectives and circumstances' (art. 10). The Conference of the Parties tasked with reviewing countries' progress (or lack thereof) in implementing the Protocol is explicitly required to take into account 'the differing circumstances, responsibilities and capabilities of the Parties and their respective commitments' (art. 13(4)). Importantly, Annex I and non-Annex I countries' commitments 

Beyond burdens and climate refugees: a stocktake of international responsibility-sharing and
South Pacific climate-induced migration

Daisy McElwain

300363544

for addressing climate change and its adverse impacts are determined in part by their respective capabilities, or their ability to pay. The other deciding factor in determining states' respective commitments under the Protocol is, of course, their historical greenhouse gas emissions.

Fast-forward to the Paris Agreement, and APP is still present in the climate change responsibility-sharing regime but significantly watered-down. The Agreement pays lipservice to the Common but Differentiated Responsibilities principle and 'different national circumstances'. However, as previously discussed, under the Nationally Determined Contributions (NDC) mechanism without Annex classifications it is up to countries with greater ability to pay to voluntarily take on greater responsibilities. The Agreement requires (or rather encourages) developed country parties to provide financial resources to assist developing country parties to implement their emissions reduction and adaptation obligations (art. 9), recognising that 'enhanced support for developing country parties will allow for higher ambition in their actions' (art. 4(5)). There is also special exemption for least developed countries (LDCs) and small island developing States who are allowed to pursue low greenhouse gas emissions development that reflects their 'special circumstances' (art. 4(6)). Article 13's transparency framework for reviewing states' implementation efforts has 'built-in flexibility' that accounts for developing countries' different capacities, and again recognises LDCs and Pacific Island States' special circumstances. Despite these nods to APP, the Agreement does not differentiate states' responsibilities according to APP but instead leaves it up to states to voluntarily take on responsibilities that are consistent with their ability to pay for climate change and its adverse impacts.

In the climate change and refugee/migration agreements analysed here, both APP- and PPPbased differentiation of responsibilities effectively require developed countries to take on greater obligations. So long as developed countries take on the greatest obligations, does it matter which avenue of differentiation we use to get there? Does it matter whether high- 

Beyond burdens and climate refugees: a stocktake of international responsibility-sharing and
South Pacific climate-induced migration

Daisy McElwain

300363544

emitting developed countries take on greater responsibilities for addressing climate-induced migration because of their historical emissions or their current capabilities? The ongoing academic and political debate on differentiation of states' environmental and refugee-related responsibilities suggests that it matters a great deal. APP overcomes some of the buy-in constraints and measurement issues associated with PPP's fault-based approach. Yet, as noted by Eckersley, APP's appeal to developed countries comes with a significant trade-off. She argues that 'the greatest virtue of the APP is also the greatest drawback from the standpoint of climate refugees'. According to Eckersley, although APP's differentiation on the basis of relative capability is far less politically contentious than PPP, the principle is 'only likely to be politically accepted if relative capability is determined subjectively by each state rather than according to objective measures such as relative GDP or the human development index... effectively convert[ing] state responsibility into a charitable responsibility to provide humanitarian relief' (Eckersley, 2015, p. 488). This is echoed by Dowd and McAdam who observe that in the refugee context 'if States are left to assess their own capacity to contribute to responsibility-sharing subjectively, pursuant to the principle of common but differentiated responsibilities, this is likely to limit its effectiveness. Having said this, States are unlikely to have it any other way' (Dowd \& McAdam, 2017b, p. 887).

How might APP be operationalised in the climate migration context? Let us consider how APP has worked (or rather not worked) in the contemporary climate change and refugee/migration regimes. In the Paris Agreement's NDC mechanism and the Refugee Compact's Global Refugee Forum we can see an 'inverse relationship between capability and political motivation' (Eckersley, 2015, p. 490). In other words, there is a significant gap between states' relative capabilities and the responsibilities that they voluntarily take on. In the contemporary climate change regime we have seen the watering-down of the Common but Differentiated Responsibilities principle and its APP criteria into self-differentiation of responsibilities. Under the Paris Agreement's NDC mechanism it is up to wealthy countries to voluntarily take on greater responsibilities for climate change that are consistent with their 

Beyond burdens and climate refugees: a stocktake of international responsibility-sharing and
South Pacific climate-induced migration

Daisy McElwain 300363544

relative capabilities. Similarly, we can point to the shortcomings of the Refugee Compact's Global Refugee Forum where states make completely voluntary contributions that (purportedly) account for national capacities and levels of development. Importantly, thus far developed countries have not voluntarily taken on (or lived up to) emissions targets that are consistent with their ability to pay under the NDC mechanism, nor have they made adequate pledges that reflect their greater capabilities at the Global Refugee Forum. Pacific communities ' sense of injustice and abandonment by the international community under the current international climate change responsibility-sharing regime is explained by $i$-Kiribati Reverend Eria Maere.

'Others are reaping the benefits of all these gases and things, but we are paying the price.... our kids are worried - where will they be in 10-15 years time? There is no love for the people of the islands.' (Uan, 2013)

Based on these contemporary examples of APP-based differentiation in practice, it seems safe to assume that if states' responsibilities for climate-induced migration are also determined on a subjective and voluntary basis there is likely to be a significant gap between states' ability to pay and their actual responsibilities. However, as noted by Eckersley and Dowd and McAdam, we are unlikely to see enforcement mechanisms for APP-based differentiation of responsibilities in the climate migration context due states' unwillingness to accept objective measures for state responsibility (Eckersley, 2015, Dowd \& McAdam, 2017b).

Let us now consider what APP-based differentiation means for Pacific communities facing the prospect of leaving their ancestral homes. Marshall Islands Pacific Climate Warrior Milañ Loeak provides insight into the deep sense of injustice and unfairness that Pacific communities feel with regard to their disproportionate vulnerability to climate change's adverse impacts. She says 'none of us who have felt the impacts of climate change should 

Beyond burdens and climate refugees: a stocktake of international responsibility-sharing and
South Pacific climate-induced migration

Daisy McElwain

300363544

continue to suffer through them just to fulfil others' interests. We don't deserve to lose our Islands'. (350 Pacific, 2014). This is echoed by Siuila Toloa, director of Tuvaluan NGO Island Care, who asks 'How often have you heard someone argue that climate change ... has no impact on anyone else? ... The small island states contribute insignificantly to global emissions, but suffer most' (Toloa, 2004). Importantly for this paper's discussion of how we might differentiate states' responsibilities vis-à-vis climate migration, from the perspective of Pacific communities this unacceptable behaviour must be reciprocated for through meaningful action (Uan, 2013). In the words of JetñilKijiner, 'Greed is punishable. Greed is remembered. As the Rotuman proverb states - the land has eyes' (Jetñil-Kijiner, 2015). This understanding of environmental degradation as both punishable and watched by mother Earth suggests that past wrongs can accumulate. From these Pacific perspectives, we can understand historical emissions as past wrongs that must be recognised. Thus, historical emitters must take on greater climate migration-related obligations as a form of reciprocal action for these injustices.

APP does not go as far as PPP's blame-based approach in meeting Pacific communities' demand for recognition of past wrongs as well as reciprocal action. While PPP satisfies the demand for both accountability and action, APP only satisfies the latter. Under the subjective and voluntary APP-based self-differentiation we see in the Paris Agreement and Global Refugee Compact, it is assumed that benevolent developed countries will decide to take on greater responsibilities for climate-induced migration. But importantly, there is no formal recognition of historical emitters' role in Pacifics' forced displacement from their homes. The end result is the same - under both APP and PPP developed countries must take on greater responsibilities - but under APP developed countries are required (or encouraged) to do so because of their relative capabilities, not because they have wronged Pacific Island States who are now bearing the brunt of climate change's adverse impacts. In sum, there is sufficient overlap between APP and Pacifics communities' demand for reciprocal action for the common principle to be considered useful for an Oceania agreement on climate 


\section{Beyond burdens and climate refugees: a stocktake of international responsibility-sharing and South Pacific climate-induced migration}

Daisy McElwain

300363544

migration. Yet, the principle falls short of Pacific communities' demand for recognition of past wrongs.

\subsubsection{Summary}

The ability to pay principle (APP) and polluter pays principle (PPP) are common responsibility-sharing principles that have overall compatibility with Pacific communities' demands for accountability and action from historical polluters. Thus, these common principles can help inform an Oceania agreement on climate-induced migration that equitably differentiates the responsibilities of Pacific Island States and neighbouring historical emitters Australia and NZ. ${ }^{10}$ However, differentiating state responsibilities for addressing climate migration is no simple task. This section's comparison of how existing agreements differentiate states' environmental and refugee responsibilities reveals a conundrum: APP is more politically feasible than PPP but does not go as far in meeting Pacific communities' demands for recognition of past (and current) wrongs, while PPP satisfies this demand for accountability but is extremely politically contentious. In addition, subjective and voluntary APP-based differentiation has feasibility issues in terms of the gap between states' ability to pay and what they will voluntarily pay. Not only is PPP's notion of climate liability a tough sell at the negotiation table, in practice it is difficult to establish causation and liability, especially in the context of climate-induced migration. There is ongoing political and

\footnotetext{
${ }^{10}$ While NZ's global carbon footprint is relatively small due to the country's small population size, both NZ and Australia have significant historical and current carbon emissions per capita (The World Bank, n.d.). Relative to their Pacific Island neighbours, NZ and Australia have large carbon footprints that render them historical emitters. The Climate Action Tracker rates both NZ and Australia's NDCs as insufficient, and as at 2 December 2019 both countries were on track to fall well short of their NDCs (Climate Action Tracker, n.d.).
} 
Beyond burdens and climate refugees: a stocktake of international responsibility-sharing and
South Pacific climate-induced migration

Daisy McElwain 300363544

academic debate on what constitutes fair and equitable responsibility-sharing. According to the Refugee Compact, its APP-based responsibility-sharing framework provides for 'more equitable, sustained and predictable distribution of contributions among States' (para. 7). The UN Framework Convention on Climate Change and Kyoto Protocol operationalise both APP and PPP under the Common but Differentiated Responsibilities principle to impose greater responsibilities on developed countries for combatting climate change's adverse impacts such as climate-induced migration. Under the Common but Differentiated Responsibilities principle, developed countries are required to take the lead because of both their relative capabilities and historical emissions. In contrast, the Paris Agreement proposes that it is best to leave it up to states to voluntarily take on responsibilities that are consistent with their ability to pay. So, whose responsibility is it to address climate-induced migration in the South Pacific? According to both APP and PPP's logics, the Oceania region's wealthy, developed countries Australia and NZ have the greatest relative capabilities and historical emissions, and therefore must take on the greatest responsibilities for climate migration. This begs the question, what are they responsible for?

\subsection{What are states responsible for?}

If high-emitting, wealthy developed countries must take on the greatest responsibilities for climate-induced migration, what exactly are they responsible for? In the climate change and refugee/migration responsibility-sharing regimes we can see three interlinked common responsibility-sharing goals that underpin states' duties and obligations in this area: prevention, emissions reduction and (funding) adaptation. Investigating the evolution of these goals in international responsibility-sharing agreements to date tells us what each goal might mean in the context of climate migration. Kovner considers emissions reduction and adaptation to be 'climate justice duties' grounded in the normative argument that wealthy 


\section{Beyond burdens and climate refugees: a stocktake of international responsibility-sharing and South Pacific climate-induced migration}

Daisy McElwain 300363544

historical emitters have a moral obligation to take on greater climate change responsibilities (Kovner, 2017, p. 27). Indeed, there is significant congruence between the common goals of prevention, emissions reduction and adaptation, and Pacific communities' demand for threepronged preventative action from developed countries that includes sincere mitigation efforts, funding adaptation in Pacific Island States and compensating for loss and damage. In addition, the common goal of prevention overlaps with Pacific Island leaders' 'urgency' narrative on climate change. This section explores states' responsibilities for emissions reduction, adaptation and preventative action in the climate migration context, and invites further research into states' compensation responsibilities. This comparative analysis brings us a step closer to identifying a set of common principles and goals that can serve as a valuable starting point for an Oceania responsibility-sharing agreement on climate migration.

\subsubsection{Prevention}

Prevention is an increasingly popular goal of responsibility-sharing for refugees/migration and climate change. Contemporary environmental and refugee responsibility-sharing agreements call on states to prevent climate change's adverse impacts and large-scale refugee situations respectively. This emerging discourse on states' responsibility to prevent in the environmental and refugee/migration contexts has significant ambiguities. Firstly, how can states prevent climate change's adverse impacts? Secondly, we must ask can states prevent these phenomena, especially when it comes to climate-induced migration? This paper defines the state responsibility to prevent in the context of climate-induced migration as a responsibility to mitigate as much as possible that encompasses two key obligations of developed countries; reducing emissions and funding adaptation. Notwithstanding its ambiguities, the responsibility to prevent is a potentially productive overlap between refugee 


\section{Beyond burdens and climate refugees: a stocktake of international responsibility-sharing and South Pacific climate-induced migration}

Daisy McElwain

300363544

and environmental agreements that highlights the need (and some political appetite) for targeted international preventative action on climate migration via responsibility-sharing.

The concept of state responsibility to prevent refugee displacement and climate change's adverse impacts raises the vital question; how can states prevent climate-induced migration? When we talk about the responsibility to prevent in this context, are we obligating (developed) states to prevent climate migration by reducing emissions, or by funding climatevulnerable Pacific Island States' adaptation programmes? It can be argued that developed countries are responsible for preventing climate migration through reducing their own emissions and funding adaptation abroad. Hathaway emphasises the need for targeted international action to 'plan for, rather than simply react to refugee movements'. She also distinguishes between human and financial responsibility-sharing in the refugee context (Hathaway, 2016). Using Hathaway's distinction, we can understand the responsibility to prevent (via emissions reduction and funding adaptation) as a primarily financial responsibility that (hopefully) comes before the human responsibility to receive climatedisplaced people. Thus, the responsibility to prevent climate-induced migration is at its core an economic obligation that requires developed countries to reduce their own emissions while funding adaption and sustainable development programmes abroad, specifically in climatevulnerable countries such as Pacific Island States.

Can states prevent climate-induced migration through targeted preventative action? Or is this an impossible task that goes beyond the reach of regional and international responsibilitysharing? As highlighted by Boas et al., although science tells us that a significant amount of Pacific peoples will indeed be displaced by climate change (along with multiple interlinked migration drivers), mass climate-induced migration is not inevitable (Boas et al., 2019).

Securitised prevention efforts focused on securing the North's borders from large numbers of 'climate refugees' from the South run the risk of rendering climate-induced migration a self- 

Beyond burdens and climate refugees: a stocktake of international responsibility-sharing and
South Pacific climate-induced migration

Daisy McElwain 300363544

fulfilling prophecy. Thus, this paper sees the state responsibility to prevent vis-à-vis climateinduced migration as not a responsibility to prevent all climate-induced displacement, but rather a responsibility to mitigate as much as possible Pacific Island States' disproportionate vulnerability to such displacement. These prevention or mitigation efforts must go beyond border protection to include supporting adaptation and development in Pacific Island States in order to mitigate the extent of climate-induced displacement; both the number of people displaced and the nature of their displacement (voluntary or involuntary mobility).

We can see the common goal of prevention in the 2018 Global Compacts on refugees and migration. The Global Compact on Refugees' 'prevention and addressing root causes' principle calls on all States and relevant stakeholders to 'tackle the root causes of large refugee situations' (para. 9). According to the Refugee Compact, protecting and caring for refugees 'importantly needs to be accompanied by dedicated efforts to address root causes' (para. 8). Again, this resonates with Pacific communities' demand for sincere three-pronged prevention efforts instead of the international community putting the onus on Pacific Island States to 'adapt' to climate change and migrate. Importantly for this paper, the Refugee Compact's prevention and root causes principle recognises that 'climate, environmental degradation and natural disasters increasingly interact with the drivers of refugee movements' and this requires early preventative action and improved international cooperation (para. 8). According to the Compact, 'eliminating root causes is the most effective way to achieve solutions' (para. 85). Indeed, at the 2019 Global Refugee Forum states and stakeholders emphasised the need to address the root causes of refugee situations (UNHCR, 2019). However, the focus was on preventing conflict-driven refugee displacement through the prevention and resolution of conflicts, rather than the targeted emissions reduction efforts and funding for adaptation and development that is needed to prevent (or at least mitigate as much as possible) climate-induced migration. 

Beyond burdens and climate refugees: a stocktake of international responsibility-sharing and
South Pacific climate-induced migration

Daisy McElwain

300363544

The Global Compact for Migration's second objective is to 'minimize the adverse drivers and structural factors that compel people to leave their country of origin' (para. 18). At the heart of this prevention objective is the Compact's stance that 'migration should never be an act of desperation' (para. 13). Specifically, the Compact commits states to ensure that 'desperation and deteriorating environments do not compel [people] to seek a livelihood elsewhere through irregular migration' (para. 18), and dedicates five paragraphs to the prevention of irregular migration relating to natural disasters, the adverse effects of climate change and environmental degradation (para. 18 (h-l)). Thus, the Compact provides for the prevention of involuntary or forced climate-induced migration (that is deemed 'irregular'). However, when it comes to climate migration it is extremely difficult to establish (in)voluntariness, or distinguish between Pacific peoples' everyday mobility and their complex climate (im)mobility decisions (see Oakes, 2019, Suliman et al., 2019).

The responsibility to prevent is a cornerstone of the international climate change regime. The idea that states can (and should) prevent or at least mitigate to some extent climate change and its adverse impacts is central to international environmental cooperation and the negotiation of relevant agreements. It can be said that optimism and the hope that humans can do something about climate change are fundamental to climate change responsibility-sharing. If the international community takes the pessimistic view that climate change's adverse impacts cannot be prevented or mitigated, then what is the point of negotiating international climate change agreements? What will bring states to the negotiation table? If the international community in effect 'gives up' on preventing climate change, the global environmental and economic consequences, and political consequences for incumbent governments, would be dire.

As early as 1992, there was a sense of urgency and growing international political consensus on the need to prevent or at least mitigate climate change and its adverse impacts. The UN 
Beyond burdens and climate refugees: a stocktake of international responsibility-sharing and South Pacific climate-induced migration

Daisy McElwain 300363544

Framework Convention on Climate Change's ultimate objective was to achieve 'stabilization of greenhouse gas concentrations in the atmosphere at a level that would prevent dangerous anthropogenic interference with the climate system' (art. 2). The Convention's Article 3(3) conveys a sense of urgency that has come to dominate (left leaning) political, academic and media discourses on climate change.

The Parties should take precautionary measures to anticipate, prevent or minimize the causes of climate change and mitigate its adverse effects. Where there are threats of serious or irreversible damage, lack of full scientific certainty should not be used as a reason for postponing such measures.

States' responsibility to prevent remains at the core of contemporary environmental responsibility-sharing agreements. While the Kyoto Protocol and Paris Agreement do not use the term 'prevent', they commit states to achieving long-term global temperature goals through individual and collective efforts to significantly reduce anthropogenic greenhouse gas emissions. Thus, the responsibility to prevent via emissions reduction is a fundamental goal of the contemporary climate change responsibility-sharing regime.

Prevention-oriented rhetoric has seen a recent surge in political popularity. Interestingly, prevention discourses are often entangled with later discussed problematic migration-asadaptation and labour migration discourses. As recently as the January 2020 Global Forum for Migration and Development (GFMD), the UN Development Programme Crisis Bureau's Assistant Secretary General and Director Asako Okai stated that there is a need for a 'prevention angle' in international development, including targeted action to ensure that migration is voluntary and socio-economically beneficial (Okai, GFMD, 21 January 2020). In addition, the prevention of forced environmental migration is one of the International Organization for Migration's institutional objectives. This commitment is accompanied by 


\section{Beyond burdens and climate refugees: a stocktake of international responsibility-sharing and South Pacific climate-induced migration}

Daisy McElwain 300363544

optimistic framing of voluntary migration that emphasises the socioeconomic 'opportunities' of climate-induced migration (Chazalnoel \& Ionesco, 2018). This optimistic framing of climate-induced migration as an opportunity for labour mobility is a common refrain in academic and policy discourses. I would counter that the complexity of (im)mobility decisions that Pacific communities face, and the divergence of multiple migration drivers with climate change, means that there is a need for targeted international preventative action that goes beyond merely rendering climate migration 'voluntary' or economically attractive.

The common goal of prevention is consistent with Pacific Island leaders' urgency narrative on climate change. We can see this urgency language in their individual and joint Pacific Islands Forum statements. The Pacific Islands Forum is an inter-governmental organisation that acts as a forum for regional cooperation. Its members include Pacific Small Island Developing States, Australia ${ }^{11}$ and NZ. The Pacific Islands Forum's 2019 Kainaki II Declaration for Urgent Climate Change Action Now is the Forum's strongest collective statement on climate change to date. The document declares that Pacific Island States are facing a 'climate crisis' and already dealing with climate change's adverse impacts, including climate-induced displacement and the resulting loss of homes and livelihoods. Importantly, the Declaration calls for bold and urgent regional and global climate change action. The Declaration states:

As Leaders of the Pacific Islands Forum, custodians of the world's largest ocean and carbon sink, and representatives of our Pacific peoples, we call for immediate action and not just discussion of ambition... Any failure to act will impact not just us, but our children and all generations to come. The time to act is now. (Pacific Islands Forum, 2019, p. 13)

\footnotetext{
${ }^{11}$ Australia's Pacific Islands Forum membership is under strain from China's security contestation and growing aid role in the Indo-Pacific region. While previously Pacific Island States' reliance on Australia for development aid gave the country leverage, Australia can no longer play the 'money card' as Pacific Island States can now turn to Beijing instead (Ellsmoor, 2019).
} 
Beyond burdens and climate refugees: a stocktake of international responsibility-sharing and
South Pacific climate-induced migration

Daisy McElwain

300363544

For Tuvalu Prime Minister Enele Sosene Sopoaga, climate change's adverse impacts already being felt by Pacific Island States such as climate-induced migration demand urgent, early preventative action in order to prevent these impacts from becoming 'irreversible'. He argued 'we must ensure that climate change is not irreversible... The plight of people displaced within countries and across borders must be addressed as a matter of urgency' (Sopoaga, Paris Signing Ceremony, April 22 2016). In the context of climate migration, we can understand irreversible damage as the displacement of entire Pacific Island State populations and the resulting loss of ties to ancestral land, cultures, languages, religions and ways of life (Mortreux \& Barnett, 2009). For Pacific communities, the need for preventative action in this area to mitigate such irreversible damage (as much as possible) is nonnegotiable. So, what exactly does this urgent preventative action that Pacific Island leaders are calling for entail?

\subsubsection{Emissions reduction}

If 'the time to act is now' (Pacific Islands Forum, 2019), as science has long been telling us, what preventative action specifically needs to be taken? Interestingly, the urgent global and regional action that is called for by Pacific Islands Forum leaders in the Kainaki II Declaration specifically includes three key elements: greenhouse gas emissions reduction, adaptation finance and compensation for loss and damage. There is clear overlap here between the Pacific Islands Forum's demand for urgent three-pronged preventative action on climate change, and the responsibility-sharing goals of emissions reduction and adaptation. I will first discuss the common goal of emissions reduction.

Reducing global greenhouse gas emissions through individual and collective emissions reduction efforts seems like the obvious silver bullet solution to anthropogenic climate change. If humans have created climate change, surely they can stop it? We have seen in the 

Beyond burdens and climate refugees: a stocktake of international responsibility-sharing and
South Pacific climate-induced migration

Daisy McElwain 300363544

(non)implementation of states' Nationally Determined Contributions (NDC) promises under the Paris Agreement (see Climate Action Tracker) while global temperature averages continue to rise at an environmentally unacceptable rate (World Meteorological Organization, 2020), that reducing emissions is far from an easy solution to climate change. International, regional and state-level emissions reduction efforts have inherent complexities. As early as 2018, the Intergovernmental Panel on Climate Change (IPCC) found that states' NDCs submitted under the Paris Agreement are not enough to limit global warming to $1.5^{\circ} \mathrm{C}$ (IPCC, 2018, p. 24). ${ }^{12}$ Indeed, Schleussner et al. note a 'clear inconsistency between the long-term goals in the Paris Agreement and near-term mitigation [emissions reduction] ambition as expressed in current INDCs' (Schleussner et al., 2016, p. 833). Furthermore, even if we are somehow successful (despite scientific projections saying otherwise) in staying below the Paris Agreement's $1.5^{\circ} \mathrm{C}$ target, climate-vulnerable countries will still be disproportionately impacted by climate change's already existing adverse impacts such as climate-induced migration. According to Gampfer, 'one of the reasons for deadlock in global climate policy is countries' disagreement on how to share the mitigation [emissions reduction] burden' (Gampfer, 2014, p. 65). At the same time, stabilising global emissions and temperatures is a fundamental driver of UN climate change responsibility-sharing efforts. Thus, the 'mitigation burden' or responsibility to reduce emissions is both a political hot potato, and a fundamental goal at the core of contemporary climate change responsibility-sharing agreements.

Emissions reduction is a common goal of contemporary climate change responsibility-sharing agreements. As previously noted, the UN Framework Convention on Climate Change's ultimate objective is stabilising greenhouse gas emissions (art. 2). Contemporary climate change agreements operationalise this objective by holding states to long-term global temperature goals (Schleussner et al., 2016). The Paris Agreement's central objective and

\footnotetext{
${ }^{12}$ This is in addition to significant gaps between countries' NDC targets and their actual emissions post-2015 (see Climate Action Tracker, n.d.).
} 

Beyond burdens and climate refugees: a stocktake of international responsibility-sharing and
South Pacific climate-induced migration

Daisy McElwain

300363544

long-term temperature goal is to hold global temperature increase 'well below $2{ }^{\circ} \mathrm{C}$ above preindustrial levels and pursuing efforts to limit the temperature increase to $1.5^{\circ} \mathrm{C}$ above preindustrial levels' in order to 'significantly reduce the risks and impacts of climate change' (art. 2(1a)). The Paris Agreement's $1.5^{\circ} \mathrm{C}$ goal goes legally and substantively further than the 2009 Copenhagen Accord's $2^{\circ} \mathrm{C}$ threshold (Schleussner et al., 2016). The increasing ambition of the international community's long-term temperature goals reflects increasing urgency in scientific projections of the severity of the adverse consequences of a $2^{\circ} \mathrm{C}$ warming level, as well as increasing political and media attention being afforded to climate-vulnerable countries such as 'sinking' Pacific Island States.

Developed countries are obligated (or politely encouraged in the case of the Paris Agreement) to take preventative action to stay below these global temperature thresholds. This includes both reducing their own emissions and providing the financial and technical support necessary for developing countries to reduce their emissions. Let us first consider the Kyoto Protocol. Mann describes the Protocol as a 'greenhouse gas abatement treaty' (Mann, 2018, p. 62). The Protocol committed Annex 1 countries to legally binding emissions reduction targets. 18 years later, the common goal of emissions reduction remained a core focus of the 2015 Paris negotiations. In the words of Obergassel et al., 'the main message from Paris was "the age of fossil fuels is over"' (Obergassel et al., 2016, p. 3). However, without the Kyoto Protocol's Annex classifications and caps on developed country emissions, the Paris Agreement did not put any caps on individual or global emissions. Lea argues that 'mitigation [emissions reduction] policy can only work if there are caps on global emissions', and therefore the Paris Agreement's $1.5^{\circ} \mathrm{C}$ goal is 'doomed to failure' (Lea, 2019, p. 10). The Paris Agreement aims for global greenhouse gas emissions to peak as soon as possible in order to achieve its long-term temperature goal (art. 4(1)). Developed country Parties are required to undertake economy-wide absolute emission reduction targets (art. 4(4)) while providing support to developing countries, recognising that 'enhanced support for developing 

Beyond burdens and climate refugees: a stocktake of international responsibility-sharing and
South Pacific climate-induced migration

Daisy McElwain

300363544

country Parties will allow for higher ambition in their [emissions mitigation] actions' (art.

4(5)). Specifically, developed country parties are encouraged to provide financial resources to assist developing country parties with emissions reduction (art. 9(1)) and relevant technology development (art. 10). The evolution of the common goal of emissions reduction underlines the difficulties of pinning down global emissions targets at the negotiation table. According to Mann, to date 'international climate negotiations have focused almost exclusively on mitigation' or emissions reduction (Mann, 2018, p. 62). Mann argues that the Kyoto Protocol is the result of a trade-off between emissions reduction and adaptation, and the latter is effectively 'left out' of the document (Mann, 2018, p. 62).

In light of climate change's adverse impacts that are already being felt by climate-vulnerable countries; case in point Pacific Island States and climate-induced migration, it is tempting to write off emissions reduction efforts as futile. Indeed, Lea critiques 'international (UN) initiatives to "control" climate change by curbing carbon dioxide emissions', concluding that 'neither the Kyoto Protocol nor the Paris Agreement have succeeded, or will succeed, in reducing global emissions, despite the rhetoric'. She sees emissions targets such as the United Kingdom's 2019 'net zero' greenhouse gas emissions target as 'futile gesture politics' (Lea, 2019, p. 7). On the other hand, optimistic scholarship has celebrated the Paris Agreement as ushering in a new era of bottom-up climate politics where environmentally concerned citizens and international norms hold states accountable to reducing their carbon emissions (see Voigt \& Ferreira, 2016, Falkner, 2016, Clémençon, 2016). Thus, emissions reduction is an academically and politically contested common goal of climate change responsibility-sharing. This paper sees emissions reduction efforts as necessary to prevent further climate changerelated damage and mitigate the severity of its already existing adverse impacts.

Emissions reduction is a key component of the Pacific Islands Forum's call for three-pronged preventative action: emissions reduction, (funding) adaptation and compensation. Indeed, the 
Beyond burdens and climate refugees: a stocktake of international responsibility-sharing and South Pacific climate-induced migration

Daisy McElwain 300363544

Paris Agreement's $1.5^{\circ} \mathrm{C}$ limit is 'an enormous negotiating victory for the most vulnerable countries, LDCs and SIDS' (Obergassel et al., 2016, p. 7). A global temperature increase limit of 'well below $1.5^{\circ} \mathrm{C}$ ' has been a key demand of the Alliance Of Small Island States since 2008 (Bjermeland, n.d.). At the 2009 Copenhagen negotiations and later the 2015 Paris negotiations, Tuvalu's Prime Minister Sopoaga gained significant media salience with his emotive campaign for the $1.5^{\circ} \mathrm{C}$ limit to avoid the 'total demise' of his home (Sims, 2015). The responsibility-sharing goal of emissions reduction is consistent with Pacific communities' demand that the international community's calls for Pacific Island States to "adapt" to climate change must be complimented by (not in lieu of) sincere emissions reduction efforts from developed countries, as well as adaptation financing (Uan, 2013). In other words, rather than putting the onus on climate-vulnerable countries such as Pacific Island States to adapt, historical emitters and developed countries with greater relative capabilities must take steps reduce their own emissions. The Pacific Islands Forum's Kainaki II Declaration emphasises emissions reduction as a crucial component of effective international and regional action on climate change in no uncertain terms, stating 'the science is non-negotiable. Urgent action by the international community to reduce greenhouse gas emissions is critical to keep us on the $1.5^{\circ} \mathrm{C}$ pathway' (Pacific Islands Forum, 2019, p. 12). Pacific Island leaders' campaign for the $1.5^{\circ} \mathrm{C}$ limit and continued diplomatic efforts to pressure developed countries to stick to this target suggests that emissions reduction must be a core goal of an Oceania agreement on climate-induced migration. Indeed, as far as Pacific Island leaders are concerned, emissions reduction is 'non-negotiable'.

\subsubsection{Adaptation}


Beyond burdens and climate refugees: a stocktake of international responsibility-sharing and South Pacific climate-induced migration

Daisy McElwain

300363544

Adaptation is a common goal of climate change responsibility-sharing. The goal encompasses both the international community's calls for climate-vulnerable countries to "adapt" to climate change, and the obligations of developed countries to fund and support this local adaptation. The IPCC defines adaptation as 'the process of adjustment to actual or expected climate and its effects' and efforts to 'moderate or avoid harm or exploit beneficial opportunities' (IPCC, 2014, p. 5). Mann provides us with valuable insights into the 'politics of adaptation' (Mann, 2018). He observes that adaptation raises questions about differentiation of responsibilities at the international negotiation table. Specifically, are developed countries obligated to fund adaptation in climate-vulnerable developing countries because of their ability to pay and/or historical responsibility? Or is it up to the latter to 'adapt' to climate change with the limited capability and resources that they have? 'The vulnerable/poor must adapt' narrative has to date dominated political, academic and media discourses. Mann provides a passionate moral critique of this problematic narrative. He argues:

'discussions of "adaptation" are almost always about how the poor must adapt. There is something terribly wrong here. Surely if "adaptation" means "correction" or "adjustment," then the most important adaptation that the world could make to address climate change would be to redistribute wealth and power to end fossil fuel use and force those responsible for climate change to reallocate the wealth its drivers have helped them accumulate... It is the world's wealthy and national elites who must "adapt" ... to deal justly with those already-irreversible impacts' (Mann, 2018, pp. 63-64)

I-Kiribati woman and activist Uan further highlights that financial, technological and political support from larger, developed neighbors is essential for Pacific Island States to effectively adapt to climate change and its adverse impacts. She observes 'the international - and donor 


\section{Beyond burdens and climate refugees: a stocktake of international responsibility-sharing and South Pacific climate-induced migration}

Daisy McElwain

300363544

- community calls on us to "adapt"... but serious and sustained adaptation is a great unknown -it requires major funds and some of the world's finest minds to point the way' (Uan, 2013). If financial, political, scientific and technological support from developed countries is necessary for Pacific Island States to implement 'serious and sustained adaptation' in response to climate change's 'already-irreversible impacts' such as climate migration, what do international responsibility-sharing agreements say about adaptation? Do they contain concrete obligations for developed countries to support their climate-vulnerable developing counterparts to adapt, or are developing countries expected to adapt to climate change on their own?

Kovner offers a useful approach to understanding state adaptation duties as a 'two-tiered system': all states first and foremost have adaptation duties within their own jurisdiction, and some states have additional global duties of adaptation towards climate-vulnerable people beyond their territories (Kovner, 2017, pp. 89-91). Kovner classes states as either netcreditors, neutral states, or net-debtors. Net-debtor states have a 'positive gap' between their adaptation responsibilities and their ability to facilitate adaptation. In other words, netdebtors' adaptation obligations exceed their domestic adaptation needs. According to Kovner's logic, net-debtor states must assist net-creditor states with a 'negative gap' between their adaptation obligations and their ability to adapt. Put simply, net-creditor states are unable to address their domestic adaptation needs and these unaddressed adaptation needs can and should be addressed by net-debtor states who are 'more responsible, more capable, and less vulnerable' (Kovner, 2017, p. 90). ${ }^{13}$ Pacific Island States vulnerable to climate-inducedmigration fall under the 'net-creditor' category. Therefore, according to Kovner's logic, netdebtor states such as neighbouring Australia and NZ should provide the necessary adaptation

\footnotetext{
${ }^{13}$ Kovner's net-debtor versus net-creditor distinction does not perfectly correspond with the dynamic developed-versus-developing dichotomy (Kovner, 2017, p. 91). Although in general net-debtors with greater adaptation responsibilities are indeed wealthy, developed countries, in some cases developing countries may be net-debtors supporting their climate-vulnerable neighbours, and developed countries may become net-creditors reliant on other states for adaptation assistance.
} 


\section{Beyond burdens and climate refugees: a stocktake of international responsibility-sharing and South Pacific climate-induced migration}

assistance (financial, political and technological) for Pacific Island States to meet their communities' adaptation needs; whether that be 'staying and fighting' (McNamara \& Farbotko, 2017) or (in)voluntarily migrating overseas.

Let us now consider how the state responsibility for (funding) adaptation has been operationalised, or not, in existing climate change responsibility-sharing agreements. Comparative analysis of these agreements reveals four sub-principles: adequate adaptation, adaptation finance, adaptation costs and country-led adaptation. First, I will take a look at the principle of 'adequate adaptation' that has become a cornerstone of international climate change responsibility-sharing cooperation. The UN Framework Convention on Climate Change commits all parties to implement 'measures to facilitate adequate adaptation to climate change' (art. 4 (1b)). Fast-forward to the Kyoto Protocol, and all parties are again obligated to implement national and regional programmes with measures to facilitate 'adequate adaptation' to climate change (art. 10 (b)). However, the Protocol neither defines what constitutes an 'adequate' amount of adaptation nor obligates states to implement this adaptation. According to Mann, the Kyoto Protocol was almost exclusively focused on emissions reduction and effectively 'left out' concrete adaptation obligations. He argues that the Protocol's 'exclusion of adaptation is actually evidence of an inability to confront the politics of adaptation' (Mann, 2018, p. 62). Adaptation obligations raise difficult questions at the negotiation table, including if and how to differentiate the adaptation responsibilities of net-creditor and net-debtor states. The Kyoto Protocol briefly nods to financial assistance for developing countries' adaptation and recognises the importance of 'adaptation technologies' (art. 10 (bi)), without obligating Annex 1 parties to provide neither financial assistance nor technologies to non-Annex 1 parties.

The Paris Agreement 'elevates the standing of adaptation in the international climate regime' (Obergassel et al., 2016, p. 4). The Agreement sets out a 'global goal on adaptation of enhancing adaptive capacity, strengthening resilience and reducing vulnerability' (art. 7(1)). 

Beyond burdens and climate refugees: a stocktake of international responsibility-sharing and
South Pacific climate-induced migration

Daisy McElwain

300363544

Interestingly, the Agreement's adaptation goal aims to 'ensure an adequate adaptation response in the context of the temperature goal' (art. 7(1)), implying that staying below the Agreement's long-term temperature goal is a benchmark for 'adequate' adaptation. Parties are encouraged to assist developing country parties to identify their adaptation needs and priorities and implement best practice adaptation programmes (art. $7(7 \mathrm{a})$ ). Like its $1.5^{\circ} \mathrm{C}$ limit, the Paris Agreement's unprecedented emphasis on the importance of national and global action to support climate-vulnerable people to adapt to climate change's adverse impacts is a 'huge success' for developing countries who have long campaigned for adaptation to be a priority on the international climate change agenda (Obergassel et al., 2015 , p. 23).

However, the Paris Agreement falls short of developing countries' demands for a collective, quantified goal on adaptation finance - simply, the Agreement does not have one (Obergassel et al., 2016). The Kyoto Protocol states that a share of the proceeds from its clean development mechanism should go towards assisting climate-vulnerable developing country parties to meet the later discussed 'costs of adaptation' (art. 12 (8)). The Paris Agreement requires developed country parties (bearing in mind that the document is not legally binding) to provide financial resources to assist developing country parties with adaptation, and other parties are encouraged to provide such support voluntarily (art. 9(1-2)). In an ideal post-Paris world, every five years from 2023 a 'global stocktake' will review and accelerate contribution cycles for adaptation and emissions reduction (Obergassel et al., 2016), and the (voluntary) national adaptation communications will 'spiral up' adaptation action and support (Obergassel et al., 2015, p. 23). Yet, without a quantified goal for substantial adaptation finance or concrete legally binding obligations for developed countries in this area, all that the Paris Agreement offers with respect to adaptation finance is recognition that support for adaptation efforts is important (art. 7(6)). As noted by Mann, 'legally speaking, this “recognition” requires little to no action' (Mann, 2018, p. 65). 

Beyond burdens and climate refugees: a stocktake of international responsibility-sharing and
South Pacific climate-induced migration

Daisy McElwain

300363544

Climate change adaptation programmes are not cheap. The Kyoto Protocol and Paris

Agreement both recognise the significant 'adaptation costs' that climate-vulnerable countries must contend with. Adaptation costs are not only economic; they can also be political, environmental or social. The UN Framework Convention on Climate Change acknowledged the need for research into the adverse economic and social consequences of climate change response strategies (art. $4(1 \mathrm{~g})$ ). The Paris Agreement's preamble more explicitly recognises that 'Parties may be affected not only by climate change, but also by the impacts of the measures taken in response to it'. The Agreement also states that 'greater adaptation needs can involve greater adaptation costs' (art. 7(4)). The Kyoto Protocol singles out small island countries as of particular concern when it comes to the adverse impacts of response measures (art. 3(14)). Thus, adaptation costs are particularly problematic for what Kovner would call net-creditor states; climate-vulnerable developing countries with adaptation needs that exceed their ability to adapt.

Not only are Pacific Island States disproportionately vulnerable to the adverse impacts of climate change, they must also deal with the economic, political, environmental and social 'adaptation costs' of adapting to these impacts. For example, in Kiribati climate migration has become a 'political tug of war', meaning that implementing or even suggesting adaptation strategies that prepare communities for planned relocation can cost politicians an election (Walters, 2019). Indeed, former Kiribati President Tong's 'Migration with Dignity' policy resulted in political backlash that played a role in the election of current President Taneti Maamau who denies the possibility of climate migration for religious reasons.

Kiribati also became economically dependent on Australia for funding for the 2003-2016 Kiribati Adaptation Programme. In terms of social consequences, adaptation policies for climate migration can trigger ontological anxieties and sometimes conflicting views in Pacific communities (Oakes, 2019) about loss of cultures, languages, religions and ways of life (Mortreux \& Barnett, 2009). 

Beyond burdens and climate refugees: a stocktake of international responsibility-sharing and
South Pacific climate-induced migration

Daisy McElwain

300363544

The principle of 'country-led adaptation' recently emerged in the Paris Agreement amid growing calls in the climate migration literature for bottom-up adaptation policy that is informed by indigenous knowledge and lived experiences of climate mobility. The Paris Agreement states that adaptation action should follow a 'country-driven approach' and be guided by 'traditional knowledge, knowledge of indigenous peoples and local knowledge systems' (art. 7(5)). This reflects an increasing push in academic and policy discourses for a bottom-up rather than top-down approach to climate change adaptation and adaptation finance. This push for country-led and community-informed adaptation policy and finance is highlighted by Walshe et al., who observe that there is a 'struggle to reconcile the mass produced and "one-size-fits-all" adaptation strategies, with the diverse, local and cultural understanding and experience of climate change' (Walshe et al., 2018, p. 317). The countryled adaptation principle's emphasis on adaptation policy that is informed by indigenous knowledge and on-the-ground realities and needs has interesting implications for Pacific Island States' internationally funded adaptation policies relating to climate-induced migration.

Can we realistically expect Pacific Island States' climate adaptation and relocation policies to be funded by no-strings-attached funding from developed country donors that do not seek benefits for themselves? History tells us that North-South development aid flows typically privilege developed country donors' needs and Western science or knowledge over the needs and indigenous knowledge of developing countries' local communities (Girvan, 2007). For example, let us consider the Kiribati Adaptation Programme as an example of adaptation finance relating to climate migration. The Programme was funded by various donors including the World Bank, Global Environment Facility, UN Development Programme, Australia and Japan (Republic of Kiribati, 2018). We can optimistically point to the Programme as an example of internationally funded and country-driven adaptation, as its first phase involved representatives from each of Kiribati's atolls proposing coping mechanisms to deal with the changes their communities have seen due to climate change. On the other hand, 


\section{Beyond burdens and climate refugees: a stocktake of international responsibility-sharing and South Pacific climate-induced migration}

Daisy McElwain 300363544

we could take the critical view that because the Programme is internationally funded, the priorities and knowledge of its wealthy donors are likely to eventually outweigh the knowledge and needs of the atoll communities. Put simply, if Pacific Island States' adaptation programmes are funded by their wealthy, developed neighbours, the programmes are likely to be primarily informed by the knowledge and needs of their developed neighbours, rather than their local communities. In this sense, there is some tension between the principles of country-led adaptation and adaptation finance.

Adaptation is a topic of much debate in the climate migration literature. I want to dive into two interesting areas of debate; migration-as-adaptation and labour mobility. Political, academic and media discourses are increasingly pushing a problematic migration-asadaptation narrative that celebrates climate-induced migration as a positive adaptation strategy or solution to climate change. Farbotko has produced extensive work both criticising and investigating the potential of the migration-as-adaptation approach in the context of South Pacific climate-induced migration. She argues that to date climate migration has been treated as either an adaptation solution, adaptation failure or necessary tragedy (Farbotko et al., 2016). By framing climate migration as an inevitable and desirable adaptation solution to climate change, the migration-as-adaptation narrative oversimplifies and overlooks the complex climate (im)mobility decisions (Farbotko, 2018a) and issues of loss and agency that Pacific communities face (Farbotko et al., 2018). Uan again provides us with insight into the spiritually distressing experience of being displaced from one's ancestral land and home:

'I have no wish to live anywhere else [than Kiribati] - this is my home, this is where my ancestors lie, and this is the only place where I can fully be the person I am-a woman of Kiribati.' (Uan, 2013) 


\section{Beyond burdens and climate refugees: a stocktake of international responsibility-sharing and South Pacific climate-induced migration}

Daisy McElwain

300363544

It is perhaps tempting to optimistically frame climate-induced migration as a positive adaptation strategy that fits neatly within the Paris goal on adaptation. If adapting to climate change is a good thing, surely Pacifics (in)voluntarily migrating to overseas is a good thing too? However, the migration-as-adaptation narrative is extremely problematic in that it effectively shifts the onus of responsibility by framing climate migration as not an adverse impact of climate change, but rather an adaptation strategy or solution. This means the onus is no longer on developed countries to mitigate climate change - instead it is up to climatevulnerable communities to move and adapt to it.

Migration-as-adaptation policy discourses have also been criticised for pushing 'labour mobility’ solutions. Labour mobility policy solutions, such as liberal labour migration schemes, effectively impose neoliberal labour management strategies on climate-displaced people (Farbotko et al., 2018). Conveniently for net-debtor states, if climate-induced migration is a desirable adaptation strategy then their adaptation responsibilities are not preventing or mitigating displacement. Instead, they are obligated to support adaptive 'labour mobility' that is economically beneficial to them.

Farbotko has recently argued that the mobility-adaptation-development nexus has potential (Farbotko et al., 2018) to open the door to policies that 'embrace both loss and hope' such as former Kiribati President Tong's Migration with Dignity policy (Farbotko et al., 2016, p. 537). However, there is much debate on the concept of 'labour mobility' that underpins Tong's efforts to up-skill i-Kiribati people for employment in Australia and NZ. Indeed, Farbotko has previously noted that "naively optimistic mobility-adaptation-development discourses risk reproducing strategies of contemporary neoliberal management of labour and shifting responsibility for successful adaptation and development onto "the vulnerable" (Farbotko et al., 2018, p. 394). Felli and Castree argue that such policies are 'focused on producing "adaptable" human subjects... of capitalist market relations' (Felli \& Castree, 2012, p. 1). This is echoed by Bettini who notes that behind the migration-as-adaptation 


\section{Beyond burdens and climate refugees: a stocktake of international responsibility-sharing and South Pacific climate-induced migration}

Daisy McElwain

300363544

narrative's 'humanistic façade' is 'the idea that to be able to adapt to climate change requires becoming fit to market rules' (Bettini, 2014, p. 190). From this critical perspective, we can see Tong's Migration with Dignity policy as serving the economic needs of Kiribati's neighbouring developed countries by effectively creating a 'climate refugee' labour force. ${ }^{14}$ Needless to say, treating Pacific communities at risk of climate-induced displacement as adaptable subjects of market relations is hardly conducive to effective policy on the issue that is informed by their needs and demands.

According to Pacific Island leaders, adaptation is a crucial component of any regional responsibility-sharing effort to address climate-induced migration. As previously discussed, developed countries taking on responsibility for funding local adaptation in Pacific Island States is a key component of Pacific Island leaders' demand for three-pronged preventative action: emissions reduction, adaptation and compensation for loss and damage. The Pacific Islands Forum's Kainaki II Declaration emphasises the need for an integrated regional approach to climate change adaptation with a specific focus on collaboration to build regional resilience.

Pacific communities have diverse perspectives on adaptation and climate mobility. Some are calling for dignified migration (Uan, 2013) while others want the international community to recognise that they are 'staying and fighting' (McNamara \& Farbotko, 2017). Here we can draw on Oakes' 2019 study of climate (im)mobility decisions that draws on primary qualitative and quantitative data from Tuvaluan, Nauruan and i-Kiribati participants to identify diverse and sometimes conflicting community perspectives on climate mobility and adaptation. From a voluntary immobility perspective that is often rooted in religious beliefs in divine intervention (Oakes, 2019), Tong's Migration with Dignity policy is seen as 'throwing

\footnotetext{
${ }^{14}$ It is important to note that Tong's Migration with Dignity policy had support from i-Kiribati communities that view migration as undesirable but necessary (Oakes, 2019). While labour mobility must be critiqued for serving receiving countries' economic interests, there is also congruence here with Pacific communities' demand for dignified migration that enables them to migrate as economic assets rather than 'burdens' for receiving countries (Farbotko et al., 2016).
} 
Beyond burdens and climate refugees: a stocktake of international responsibility-sharing and South Pacific climate-induced migration

Daisy McElwain

300363544

in the towel' or giving up (Walters, 2019). For others, preparing for planned relocation is vital to ensure that climate migration is dignified and 'on their terms' (Oakes, 2019).

Community-level resistance to adaptation strategies that treat climate migration as inevitable is evident in Jetñil-Kijiner's poem 'There's a journalist here' (Jetñil-Kijiner, 2016). JetñilKijiner speaks about her experience of being interviewed by Western journalists and academics who arrive at the Marshall Islands with preconceived views of climate migration as a matter of inevitable migration-as-adaptation and Pacifics as passive victims of climate change who must move.

'they want to hear about

your old old house

how it collapsed like

a lung as the water

rushed in

they don't [want] to hear

that maybe you're

imaging [sic]

a house

with new doors

new windows

on a grassy hillside

they don't want to hear that, weeks later you found your

breath filling and expanding 


\section{Beyond burdens and climate refugees: a stocktake of international responsibility-sharing and South Pacific climate-induced migration}

Daisy McElwain

300363544

your lungs that all you want

now is to move forward'

In light of Pacific communities' complex perspectives on climate mobility and adaption, how might the common responsibility-sharing goal of (funding) adaptation work in the context of South Pacific climate-induced migration? We have seen in the negotiation of existing international climate change agreements that the collective, quantified goal on adaptation finance that has long been campaigned for by developing countries struggles to make it past the negotiation table. However, Pacific Island leaders' ongoing campaign for meaningful adaptation finance suggests that despite its negotiation difficulties we can expect adaptation finance to be at the top of the agenda for an Oceania agreement on climate migration. Furthermore, the diversity of Pacific perspectives on climate mobility and adaption clearly shows us that top-down adaptation strategies that fail to account for local needs will be woefully inadequate. Instead, internationally funded climate adaptation strategies must be country-led and community-informed.

Based on Pacific communities' needs and demands when it comes to adaptation, we can understand developed countries' adaptation finance obligations in the climate migration context as two-pronged. Firstly, wealthy historical emitters must fund efforts to mitigate displacement by funding local adaptation strategies such as building sea walls to deal with increasingly frequent and intense storm surges. Secondly, they must fund programmes for planned relocation and dignified migration. This two-pronged approach to funding adaptation efforts that both mitigate and prepare for dignified climate-induced migration recognises the agency of Pacific peoples who may not want to move. 


\section{Beyond burdens and climate refugees: a stocktake of international responsibility-sharing and South Pacific climate-induced migration}

Daisy McElwain

300363544

\subsubsection{Summary}

This section's analysis tells us that the three common responsibility-sharing goals of prevention, emissions reduction and (funding) adaptation are a valuable starting point for an Oceania agreement on climate-induced migration. There is significant congruence between these three common goals and Pacific Island leaders' and communities' demands regarding developed countries' responsibilities vis-à-vis climate migration. The Pacific Islands Forum's 2019 Kainaki II Declaration in no uncertain terms calls for three-pronged urgent preventative action on climate change that spans three key elements: emissions reduction, adaptation and compensation for loss and damage. Climate mobility is a complex issue that demands more than the cyclic knee-jerk reactive policy that seems to dominate international (in)action on climate migration. South Pacific climate-induced migration clearly necessitates early and urgent preventative action from the regional Oceania community and wider international community. This section's discussion of state responsibilities for addressing climate migration shows us that an Oceania agreement in this area must recognise Pacific Island leaders and communities' demands for sincere emissions reduction efforts and adaptation finance. Indeed, targeted regional preventative action on climate migration is not only in the interest of Pacific communities who may have to move - it is also in the interest of receiving neighbouring countries Australia and NZ to both mitigate and prepare for dignified climateinduced migration.

\section{Findings and discussion}

This thesis is essentially a quest to discover if there is a 'sweet spot' when it comes to responsibility-sharing and South Pacific climate-induced migration. This analytical 'sweet 


\section{Beyond burdens and climate refugees: a stocktake of international responsibility-sharing and South Pacific climate-induced migration}

Daisy McElwain

spot' refers to the degree of overlap between my two variables: international responsibilitysharing agreements on climate change and refugees/migration, and the needs and demands of Pacific communities. More specifically, I ask: where international responsibility-sharing agreements on climate change and refugees/migration overlap, can we identify a set of common responsibility-sharing principles and goals that might inform an effective Oceania agreement on climate-induced migration? And importantly, to what extent are these common principles and goals compatible with the needs and demands of Pacific communities dealing with the emerging reality of climate mobility? In other words, is responsibility-sharing a useful avenue for community-informed agreements and policy to address South Pacific climate migration?

My findings tell us that responsibility-sharing is indeed useful in the South Pacific climate migration context. I find identify five common responsibility-sharing goals and principles in existing international agreements on climate change and refugees/migration that have significant congruence with the needs and demands of Pacific communities at risk of climateinduced displacement. Where international agreements on climate change and refugees/migration overlap I identify two common principles: the ability to pay principle and polluter pays principle, and three common goals: prevention; adaptation and emissions reduction. Importantly, I find that there is significant overlap between these five principles and goals, and the needs and demands of Pacific communities who are facing the prospect of leaving their homes. Thus, these responsibility-sharing principles and goals provide us with a valuable starting point for an effective Oceania agreement on climate-induced migration that is equipped to deal with the needs of those who may be displaced.

Compatibility with the needs and demands of Pacific communities is a key determinant of the effectiveness of policy and agreements in this area. Therefore, given their congruence with Pacific communities' needs and demands, we can say that the ability to pay principle and polluter pays principle, and goals of prevention, emissions reduction and adaptation are key 


\section{Beyond burdens and climate refugees: a stocktake of international responsibility-sharing and South Pacific climate-induced migration}

Daisy McElwain

300363544

components of an effective Oceania agreement on climate migration. Without overlap between these responsibility-sharing principles and the needs of communities at risk of climate-induced displacement, this paper's findings would be a set of responsibility-sharing principles that perhaps look attractive on paper but in reality would inform policies and agreements that are fundamentally incompatible with the on-the-ground realities and needs of those who may have to leave their homes. Because my research finds that there is significant overlap between the international responsibility-sharing agreements, their common principles and goals, and Pacific communities' needs and demands, we can confidently move forward with the five common responsibility-sharing goals and principles as key components of an effective Oceania agreement on climate-induced migration that is equipped to address the needs and demands of those who may be displaced.

My findings show us that there is indeed a 'sweet spot', or significant area of overlap, between my two key variables; common responsibility-sharing principles and goals, and Pacific communities' needs and demands. The diagram on the next page (Diagram 1) maps the five common responsibility-sharing principles and goals in terms of their relevance to international agreements on climate change and/or refugees/migration and their compatibility with Pacific communities' needs and demands. The diagram demonstrates that there is a significant degree of overlap between a) international responsibility-sharing agreements on climate change and refugees/migration, and b) the agreements' common responsibilitysharing principles and goals and Pacific communities' needs and demands. 
Beyond burdens and climate refugees: a stocktake of international responsibility-sharing and South Pacific climate-induced migration

Daisy McElwain

300363544

\section{Diagram 1: overlap between international responsibility-sharing agreements and the needs and demands of Pacific communities}

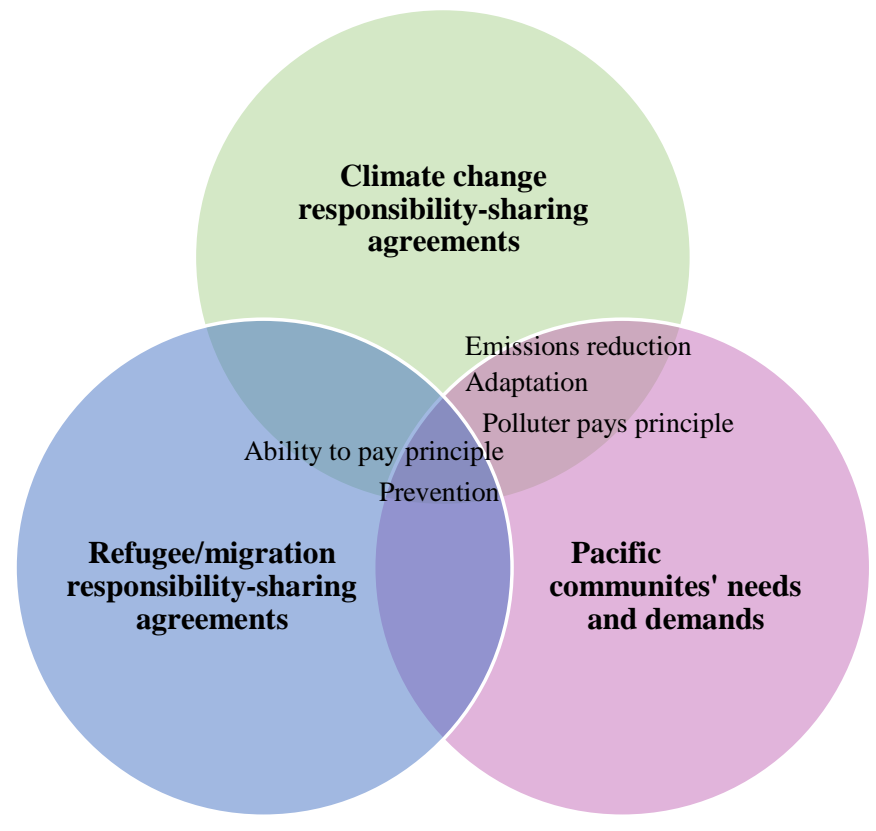

Interestingly, this 'sweet spot' or degree of overlap between the variables is larger than I initially hypothesised. The climate migration case study is interesting because it brings together the climate change and refugee/migration responsibility-sharing regimes. In diagram 1 we can see that the polluter pays principle, emissions reduction and adaptation finance are specific to climate change responsibility-sharing agreements but useful in addressing Pacific communities' needs and demands in the climate migration context. In other words, climate migration renders environmental principles and goals (and their accompanying notions of climate liability and environmental mitigation) newly relevant to international cooperation on migration. Thus, my findings are a potentially fruitful starting point for effective policy and 


\section{Beyond burdens and climate refugees: a stocktake of international responsibility-sharing and South Pacific climate-induced migration}

Daisy McElwain

300363544

agreements in this area as international cooperation evolves to deal with the emerging issue of climate-induced migration.

These findings come with the caveat of political feasibility and implementation issues. The evolution of responsibility-sharing in the international climate change and refugee/migration regimes to date clearly shows us that this model of cooperation has inherent negotiation difficulties. The ability to pay principle, polluter pays principle, prevention, adaptation finance and emissions reduction imply politically contentious concepts of climate liability and climate change and refugee obligations or 'burdens' that struggle to make it past the international negotiation table. Therefore, these common responsibility-sharing principles might be useful for developing locally informed climate migration policy and agreements, but we must recognise that they are a tough sell politically. Ongoing debate on the differentiation of states' environmental and refugee responsibilities, not to mention states' shirking of these obligations, means that responsibility-sharing is not an easy task. I find that political popularity and compatibility with the needs of communities at risk of displacement tend not to go hand-in-hand.

For example, the polluter pays principle assigns more blame to developed countries than the ability to pay principle and is correspondingly less popular at the international negotiation table. Thus, equitable differentiation of states' climate migration responsibilities is likely to encounter obstacles at the international negotiation table. Furthermore, another key finding of this research is that climate migration's complexities, such as difficulties in pinpointing clear causation and assigning blame, mean that the common responsibility-sharing principles and goals have significant implementation issues that must be addressed. In sum, responsibilitysharing is not the ideal nor is it the only solution to the South Pacific region's emerging issue of climate-induced migration, but my findings show that it is a useful place for us to start. 

Beyond burdens and climate refugees: a stocktake of international responsibility-sharing and
South Pacific climate-induced migration

Daisy McElwain

300363544

Let us take a moment to understand how we arrived at these findings. This paper is guided by three analytical steps that are applied to each common responsibility-sharing principle or goal. Firstly, I conduct comparative analysis of relevant international agreements to identify common responsibility-sharing principles and outline their evolution in international agreements to date. Secondly, I situate these principles in the contentious academic and political debates that surround responsibility-sharing. Thirdly, in order to determine how useful (or not) each responsibility-sharing principle and goal might be in the South Pacific climate migration context, I take a critical look at their compatibility with the needs and demands of Pacific communities at risk of climate-induced displacement and consider how each principle and goal might be operationalised in practice.

Differentiating states' environmental responsibilities and obligations vis-à-vis climateinduced migration is no simple task. The ability to pay principle (APP) and polluter pays principle (PPP) are common responsibility-sharing principles that are at the heart of ongoing academic and political debate on how and if we ought to differentiate states' environmental responsibilities. Diagram 1 demonstrates that both APP and PPP have overall compatibility with Pacific communities' demands for accountability and action from historical polluters. However, I find that there is a conundrum: APP is more politically feasible than PPP but does not go as far in meeting Pacific communities' demands for recognition of past (and current) wrongs, while PPP satisfies this demand for accountability but is extremely politically contentious and difficult to operationalise in terms of pinpointing causation and liability. Furthermore, the voluntary APP-based differentiation that we have seen in the international climate change and migration regimes to date has feasibility issues in terms of the gap between states' ability to pay and what they will choose pay. Despite their differences, APP and PPP have one thing in common: they both assign the greatest responsibilities for addressing climate migration to high-emitting developed countries who are the most capable and historically responsible. In the Oceania region this means that Australia and NZ have the greatest obligations for addressing climate-induced migration. 
Beyond burdens and climate refugees: a stocktake of international responsibility-sharing and South Pacific climate-induced migration

Daisy McElwain

300363544

South Pacific climate-induced migration clearly necessitates urgent preventative regional (and international) action. The three common responsibility-sharing goals of prevention, emissions reduction and (funding) adaptation are key ingredients of an effective Oceania agreement on climate migration. There is clear congruence between these goals and the Pacific Islands Forum's 2019 Kainaki II Declaration's demand for three-pronged urgent preventative action on climate change. Diagram 1 demonstrates that prevention has developed as a responsibility-sharing goal in both the climate change and refugee/migration regimes and now satisfies Pacific Island leaders and communities' demands for targeted preventative action on climate migration. The common goals of emission reduction and adaptation finance were previously specific to environmental cooperation, but now have importance and relevance in the migration field as it evolves to deal with climate migration. The responsibility-sharing goals of prevention, adaptation and emissions reduction bring us a step closer to meeting the demands of communities who may be displaced in the South Pacific region. Thus, an effective Oceania agreement on climate-induced migration must facilitate early preventative action and obligate the region's most capable and historically responsible states to take on greater responsibilities for sincere emissions reduction efforts and (funding) adaptation. 


\section{Beyond burdens and climate refugees: a stocktake of international responsibility-sharing and South Pacific climate-induced migration}

Daisy McElwain

300363544

\section{Conclusion}

In conclusion, my research finds that responsibility-sharing is a valuable starting point for effective policy and agreements that deal with the South Pacific region's emerging issue of cross-border climate-induced migration. More specifically, where international agreements on climate change and refugees/migration overlap I identify five common responsibilitysharing principles and goals: the ability to pay principle (APP), polluter pays principle (PPP), prevention, adaptation and emissions reduction. These responsibility-sharing principles have significant congruence with Pacific communities' needs and demands, and thus provide us with a valuable starting point for an Oceania agreement on climate migration that is informed first and foremost by the needs of those who may have to leave their homes. In this paper I ask who is the most responsible for addressing climate migration? And what are they responsible for? Both APP and PPP assign the greatest responsibilities for addressing climate migration to high-emitting developed countries who are the most capable (in terms of financial and technological capabilities) and historically responsible (greenhouse gas emissions). Pacific Island leaders and communities' demands tell us that an effective Oceania agreement on climate migration must obligate the region's most capable and historically responsible states, Australia and NZ, to take on greater responsibilities for prevention, sincere emissions reduction efforts and (funding) adaptation. These responsibility-sharing principles and goals are vital components of locally informed and culturally responsive policy that recognises the agency of Pacific communities who are facing the prospect of leaving their ancestral homes. Further research is needed into regional responsibility-sharing agreements on migration, compensation for loss and damage and what climate mobility means for Pacific women. 
Beyond burdens and climate refugees: a stocktake of international responsibility-sharing and South Pacific climate-induced migration

Daisy McElwain

300363544

Responsibility-sharing is by no means a silver bullet solution to climate migration. The evolution (or rather watering-down) of responsibility-sharing in the international climate change and refugee/migration regimes to date clearly shows us that equitable responsibilitysharing is a tough sell at the international negotiation table. However, the alternative is unequitable differentiation of responsibilities that enables high-emitting countries to continue to pollute and places the onus on Pacific Island States to adapt and move. As international environmental cooperation evolves to deal with the climate-induced displacement of people from their homes, political and academic discourses must shift the narrative from states shirking the 'climate refugee burden' to equitable sharing of state responsibilities and obligations. 
Beyond burdens and climate refugees: a stocktake of international responsibility-sharing and South Pacific climate-induced migration

\section{Bibliography}

350 Pacific. (2014, October 17). Pacific Climate Warriors from 12 countries blockade world's largest coal port. https://350pacific.org/pacific-climate-warriors-from12countries-blockade-worlds-largest-coal-port/

Aleinikoff, A., Arnold-Fernandez, E., Goodwin-Gill, G., Karageorgiu, E., GammeltoftHansen, T., \& Zamore, L. (2017, October 2). Explanatory Note on the Final Conclusions of the Experts Initiative on the Global Compact on Refugees. Experts Initiative on the Global Compact on Refugees, Zolberg Institute on Migration and Mobility, The New School. https://www.unhcr.org/5a181fb37.pdf

Bettini, G. (2014). Climate migration as an adaption strategy: De-securitizing climateinduced migration or making the unruly governable? Critical Studies on Security, 2(2), 180-195. https://doi.org/10.1080/21624887.2014.909225

Bjermeland, M. (n.d.). The story of $1.5^{\circ} \mathrm{C}$. Center for International Climate Research. Retrieved October 5, 2020, from https://cicero.oslo.no/en/understanding-onepointfive/the-story-of-15\#

Boas, I., Farbotko, C., Adams, H., Sterly, H., Bush, S., van der Geest, K., Wiegel, H., Ashraf, H., Baldwin, A., Bettini, G., Blondin, S., de Bruijn, M., Durand-Delacre, D., Fröhlich, C., Gioli, G., Guaita, L., Hut, E., Jarawura, F. X., Lamers, M., ... Hulme, M. (2019). Climate migration myths. Nature Climate Change, 9(12), 901-903. https://doi.org/10.1038/s41558-019-0633-3

Boyte, R. (2010). Common but Differentiated Responsibilities: Adjusting the Developing/Developed Dichotomy in International Environmental Law. New Zealand Journal of Environmental Law, 14, 63-102.

Burns, W. (2002). Pacific Island Developing Country Water Resources and Climate Change. 
Beyond burdens and climate refugees: a stocktake of international responsibility-sharing and South Pacific climate-induced migration

Daisy McElwain 300363544

In The World's Water 2002-2003: The Biennial Report On Freshwater Resources (pp. 113-127). Island Press.

Caney, S. (2005). Cosmopolitan Justice, Responsibility, and Global Climate Change. Leiden Journal of International Law, 18.

Caney, S. (2010). Climate change and the duties of the advantaged. Critical Review of International Social and Political Philosophy, 13(1), 203-228.

Chazalnoel, M. T., \& Ionesco, D. (2018). A moment of opportunity to define the global governance of environmental migration: Perspectives from the International Organization for Migration. In Routledge Handbook of Environmental Displacement and Migration (pp. 426-429). Routledge. https://doi.org/10.4324/9781315638843-35

Clémençon, R. (2016). The Two Sides of the Paris Climate Agreement: Dismal Failure or Historic Breakthrough? The Journal of Environment \& Development, 25(1), 3-24. https://doi.org/10.1177/1070496516631362

Climate Action Tracker. (n.d.). Retrieved April 20, 2020, from https://climateactiontracker.org/

Convention Relating to the Status of Refugees. (1951).

Dolla, S. (2015). International legal protection for climate refugees: Where lies the haven for the Maldivian people? Journal of Sustainable Development Law and Policy (The), 6(1), 1-30. https://doi.org/10.4314/jsdlp.v6i1.1

Dowd, R., \& McAdam, J. (2017a). International Cooperation and Responsibility Sharing to Combat Climate Change: Lessons for International Refugee Law. Melbourne Journal of International Law, 18(2), 180-218.

Dowd, R., \& McAdam, J. (2017b). International Cooperation and Responsibility-Sharing to Protect Refugees: What, why and how? International \& Comparative Law Quarterly, 66(4), 863-892. https://doi.org/10.1017/S0020589317000343 
Beyond burdens and climate refugees: a stocktake of international responsibility-sharing and South Pacific climate-induced migration

Daisy McElwain 300363544

Eckersley, R. (2015). The common but differentiated responsibilities of states to assist and receive 'climate refugees.' European Journal of Political Theory, 14(4), 481-500.

Ellsmoor, J. (2019, August 13). Pacific Island Leaders Gather In Tuvalu Amid Australian Climate Controversy. Forbes. Retrieved March 8, 2020, from https://www.forbes.com/sites/jamesellsmoor/2019/08/13/pacific-island-leadersgatherin-tuvalu-amid-australian-climate-controversy/

Falkner, R. (2016). The Paris Agreement and the new logic of international climate politics. International Affairs, 92(5), 1107-1125. https://doi.org/10.1111/1468-2346.12708

Farbotko, C. (2010a). 'The global warming clock is ticking so see these places while you can': Voyeuristic tourism and model environmental citizens on Tuvalu's disappearing islands. Singapore Journal of Tropical Geography, 31(2), 224-238. https://doi.org/10.1111/j.1467-9493.2010.00392.x

Farbotko, C. (2010b). Wishful sinking: Disappearing islands, climate refugees and cosmopolitan experimentation. Asia Pacific Viewpoint, 51(1), 47-60. https://doi.org/10.1111/j.1467-8373.2010.001413.x

Farbotko, C. (2012). Book review: Climate Change and Displacement: Multidisciplinary Perspectives. Progress in Human Geography, 36(6), 833-835. https://doi.org/10.1177/0309132511432085

Farbotko, C. (2018a). Voluntary immobility: Indigenous voices in the Pacific. Forced Migration Review; Oxford, 57, 81-83.

Farbotko, C. (2018b). Climate change and national security: An agenda for geography. Australian Geographer, 49(2), 247-253. https://doi.org/10.1080/00049182.2017.1385119

Farbotko, C., \& Lazrus, H. (2012a). The first climate refugees? Contesting global narratives of climate change in Tuvalu. Global Environmental Change, 22(2), 382-390. https://doi.org/10.1016/j.gloenvcha.2011.11.014 
Beyond burdens and climate refugees: a stocktake of international responsibility-sharing and South Pacific climate-induced migration

Farbotko, C., \& Lazrus, H. (2012b). The first climate refugees? Contesting global narratives of climate change in Tuvalu. Global Environmental Change, 22(2), 382-390. https://doi.org/10.1016/j.gloenvcha.2011.11.014

Farbotko, C., McMichael, C., Dun, O., Ransan-Cooper, H., McNamara, K. E., \& Thronton, F. (2018). Transformative mobilities in the Pacific: Promoting adaptation and development in a changing climate. Asia \& the Pacific Policy Studies, 5(3), 393-407.

Farbotko, C., Stratford, E., \& Lazrus, H. (2016). Climate migrants and new identities? The geopolitics of embracing or rejecting mobility. Migrantes Climáticos y Nuevas Identidades? La Geopolítica de Aceptar o Rechazar La Movilidad., 17(4), 533-552. https://doi.org/10.1080/14649365.2015.1089589

FBI director: China is "greatest threat" to US. (2020, July 8). BBC News. Retrieved February 9, 2020, from https://www.bbc.com/news/world-us-canada-53329755

Felli, R., \& Castree, N. (2012). Neoliberalising Adaptation to Environmental Change:

Foresight or Foreclosure? Environment and Planning A: Economy and Space, 44(1), 1-4. https://doi.org/10.1068/a44680

Gampfer, R. (2014). Do individuals care about fairness in burden sharing for climate change mitigation? Evidence from a lab experiment. Climatic Change, 124(1-2), 65-77. http://dx.doi.org.helicon.vuw.ac.nz/10.1007/s10584-014-1091-6

Gardiner, S. (2011). A Perfect Moral Storm: The Ethical Tragedy of Climate Change. Oxford University Press.

Girvan, N. (2007). Power Imbalances and Development Knowledge [University of the West Indies]. https://www.oecd.org/site/oecdgfd/39447872.pdf Global

Compact for Safe, Orderly and Regular Migration. (2018).

Global Compact on Refugees. (2018). 
Beyond burdens and climate refugees: a stocktake of international responsibility-sharing and South Pacific climate-induced migration

Hathaway, J. (2016, February 29). A global solution to a global refugee crisis.

OpenDemocracy.

https://www.opendemocracy.net/en/openglobalrightsopenpage/global-solution-toglobal-refugee-crisis/

Høeg, E., \& Tulloch, C. D. (2019). Sinking Strangers: Media Representations of Climate

Refugees on the BBC and Al Jazeera. Journal of Communication Inquiry, 43(3), 225248. https://doi.org/10.1177/0196859918809486

Inder, C. (2017). The Origins of 'Burden Sharing' in the Contemporary Refugee Protection Regime. International Journal of Refugee Law, 29(4), 523-554. https://doi.org/10.1093/ijrl/eex047

Ineli-Ciger, M. (2019). The Global Compact on Refugees and Burden Sharing: Will the Compact Address the Normative Gap Concerning Burden Sharing? Refugee Survey Quarterly, 38(2), 115-138. https://doi.org/10.1093/rsq/hdz003

Intergovernmental Panel on Climate Change. (2014). AR5 Climate Change 2014: Impacts, Adaptation, and Vulnerability. Intergovernmental Panel on Climate Change. Intergovernmental Panel on Climate Change. (2018). Global Warming of $1.5^{\circ} \mathrm{C}$ : IPCC Special Report. Intergovernmental Panel on Climate Change.

Jetñil-Kijiner, K. (2015, July 6). Luerkoklik and the Role of the Land in the Climate Movement. KE KAUPU HEHI ALE. https://www.kathyjetnilkijiner.com/luerkoklikand-the-role-of-the-land-in-the-climatemovement/

Jetñil-Kijiner, K. (2016, March 25). On Birthing New Life, and Fresh Possibilities. Kathy Jetñil-Kijiner. Retrieved March 20, 2020, from https://www.kathyjetnilkijiner.com/on-birthing-new-life-and-freshpossibilities/

Ji, Z., \& Sha, F. (2015). The challenges of the post-COP21 regime: Interpreting CBDR in the 
Beyond burdens and climate refugees: a stocktake of international responsibility-sharing and South Pacific climate-induced migration

INDC context. International Environmental Agreements: Politics, Law and Economics; Dordrecht, 15(4), 421-430.

http://dx.doi.org.helicon.vuw.ac.nz/10.1007/s10784-015-9303-8

Karasapan, O. (2020, January 27). Sharing the burden of the global refugee crisis. Brookings.

https://www.brookings.edu/blog/future-development/2020/01/27/sharing-the-

burdenof-the-global-refugee-crisis/

Kovner, N. (2017). Migration in a Warming World: On the Responsibility and Obligations of States towards Climate Change Immigrants. London School of Economics.

Kyoto Protocol to the United Nations Framework Convention on Climate Change, (1997)

Lea, R. (2019). Carbon futility: Five Essays on Climate Policy. The Global Warming Policy Foundation.

Lieberman, A. (2015, December 23). Where will the climate refugees go? Al Jazeera.

https://www.aljazeera.com/indepth/features/2015/11/climate-

refugees151125093146088.html

Mann, G. (2018). Climate Leviathan: A Political Theory of our Planetary Future. Verso. http://ebookcentral.proquest.com/lib/vuw/detail.action?docID=5213244

March, J. G., \& Olsen, J. P. (2011). The Logic of Appropriateness. In The Oxford Handbook of Political Science. https://doi.org/10.1093/oxfordhb/9780199604456.013.0024

Mayer, B. (2016). The Concept of Climate Migration: Advocacy and its Prospects. In The Concept of Climate Migration. Edward Elgar Publishing. https://wwwelgaronlinecom.helicon.vuw.ac.nz/view/9781786431721/14_chapter4.xhtml

McAdam, J., \& Loughry, M. (2009, June). We aren't refugees. Inside Story. https://insidestory.org.au/we-arent-refugees/

McElwain, D. (2019). Yazidi Refugee Women: Gender-specific migration challenges and post-transit limbo. Victoria University of Wellington. 
Beyond burdens and climate refugees: a stocktake of international responsibility-sharing and South Pacific climate-induced migration

McElwain, D. (2020). Literature Review: The securitisation of climate-induced migration. Victoria University of Wellington.

McNamara, K. E. (2015). Cross-border migration with dignity in Kiribati. Forced Migration Review, 49.

McNamara, K. E., \& Farbotko, C. (2017). Resisting a 'Doomed' Fate: An analysis of the Pacific Climate Warriors. Australian Geographer, 48(1), 17-26. https://doi.org/10.1080/00049182.2016.1266631

Migration Data Portal. (2020, June 10). Environmental Migration. https://migrationdataportal.org/themes/environmental_migration

Moravcsik, A. (1997). Taking Preferences Seriously: A Liberal Theory of International Politics. International Organization, 51(4), 513-553. JSTOR.

Mortreux, C., \& Barnett, J. (2009). Climate change, migration and adaptation in Funafuti, Tuvalu. Global Environmental Change, 19(1), 105-112. https://doi.org/10.1016/j.gloenvcha.2008.09.006

New York Declaration for Refugees and Migrants. (2016).

New Zealand Government. (2018a). Cabinet Paper on Pacific climate change-related displacement and migration.

New Zealand Government. (2018b). The Climate Crisis: Defence readiness and responsibilities.

https://www.defence.govt.nz/assets/Uploads/66cfc96a20/ClimateChange-andSecurity-2018.pdf

$\mathrm{Ng}$, A. (2020, January 13). China is the "most serious threat" to the United States, says former security advisor to Obama. CNBC.

https://www.cnbc.com/2020/01/13/chinais-the-most-serious-threat-to-the-unitedstates-james-jones.html 
Beyond burdens and climate refugees: a stocktake of international responsibility-sharing and South Pacific climate-induced migration

Oakes, R. (2019). Culture, climate change and mobility decisions in Pacific Small Island Developing States. Population and Environment, 40(4), 480-503. https://doi.org/10.1007/s11111-019-00321-w

Obergassel, W., Arens, C., Hermwille, L., Kreibich, N., Mersmann, F., Ott, H., \& WangHelmreich, H. (2015). Phoenix from the ashes: An analysis of the Paris Agreement to the United Nations Framework Convention on Climate Change - Part I. ELM, 27(6), 243-262.

Obergassel, W., Arens, C., Mersmann, F., Ott, H., Wang-Helmreich, H., \& Kreibich, N. (2016). Phoenix from the ashes: An analysis of the Paris Agreement to the United Nations Framework Convention on Climate Change - Part II. ELM, 28.

Pacific Islands Forum. (2019). 50th Pacific Islands Forum Communique.

https://www.forumsec.org/wp-content/uploads/2019/08/50th-Pacific-IslandsForumCommunique.pdf

Page, E. (2012). Give it up for climate change: A defence of the beneficiary pays principle.

International Theory, 4(2), 300-330.

Paris Agreement Under the United Nations Framework Convention on Climate Change, (2015).

Parker, D. (2008). Sharing the burden of climate change. Policy Quarterly, 4(4), Article 4. https://doi.org/10.26686/pq.v4i4.4273

Perumal, N. (2018). "The place where I live is where I belong": Community perspectives on climate change and climate-related migration in the Pacific island nation of Vanuatu. Island Studies Journal, 13(1), 45-64. Gale Academic OneFile.

Pickering, J., \& Barry, C. (2012). On the concept of climate debt: Its moral and political value. Critical Review of International Social and Political Philosophy, 15(5), 667685. https://doi.org/10.1080/13698230.2012.727311 
Beyond burdens and climate refugees: a stocktake of international responsibility-sharing and South Pacific climate-induced migration

Rajamani, L. (2012). Developing countries and compliance in the climate regime. In Promoting Compliance in an Evolving Climate Regime (pp. 367-394). Cambridge University Press.

Rajamani, L. (2016). The 2015 Paris Agreement: Interplay Between Hard, Soft and NonObligations. Journal of Environmental Law, 28(2), 337-358.

https://doi.org/10.1093/jel/eqw015

Ransan-Cooper, H., Farbotko, C., McNamara, K. E., Thornton, F., \& Chevalier, E. (2015). Being(s) framed: The means and ends of framing environmental migrants. Global Environmental Change, 35, 106-115.

https://doi.org/10.1016/j.gloenvcha.2015.07.013

Republic of Kiribati. (2018). Kiribati Adaptation Program.

www.climate.gov.ki/category/action/adaptation/kiribati-adaptation-program/

Schlein, L. (2019, December 18). Billions of Dollars and In-Kind Contributions Pledged at Global Refugee Forum. Voice of America.

https://www.voanews.com/europe/billions-dollars-and-kind-contributionspledgedglobal-refugee-forum

Schleussner, C.-F., Rogelj, J., Schaeffer, M., Lissner, T., Licker, R., Fischer, E. M., Knutti, R., Levermann, A., Frieler, K., \& Hare, W. (2016). Science and policy characteristics of the Paris Agreement temperature goal. Nature Climate Change, 6(9), 827-835. https://doi.org/10.1038/nclimate3096

Schulz, M. (2016). Logic of Consequences and Logic of Appropriateness. In M. Augier \& D.

J. Teece (Eds.), The Palgrave Encyclopedia of Strategic Management (pp. 1-8).

Palgrave Macmillan UK. https://doi.org/10.1057/978-1-349-94848-2_544-1

Sewell, A. (2019, December 20). Key takeaways from the first Global Refugee Forum. The New Humanitarian.

https://www.thenewhumanitarian.org/news/2019/12/20/Globalrefugee-forumtakeaways 
Beyond burdens and climate refugees: a stocktake of international responsibility-sharing and South Pacific climate-induced migration

Sims, A. (2015, December 2). Pacific Island Tuvalu calls for 1.5 degrees global warming limit or faces "total demise." The Independent. https://www.independent.co.uk/news/world/australasia/pacific-island-tuvalu-calls-for15-degrees-global-warming-limit-or-face-total-demise-a6756941.html

Suliman, S., Farbotko, C., Ransan-Cooper, H., McNamara, K. E., Thornton, F., McMichael, C., \& Kitara, T. (2019). Indigenous (im)mobilities in the Anthropocene. Mobilities, 14(3), 298-318.

The Pacific Islands. (n.d.). Cop23. Retrieved April 18, 2020, from https://cop23.com.fj/fijiand-the-pacific/pacific-islands/

The World Bank. (n.d.). The World Bank Data-CO2 emissions (metric tons per capita). https://data.worldbank.org/indicator/EN.ATM.CO2E.PC?locations=NZ

Toloa, S. (2004). Transcripts from the Climate Justice Tour: Energy, Poverty and the Rising Sea Friends of the Earth - Climate Justice Tour.

Tong, A. (2018, October 10). While my island nation sinks, Australia is doing nothing to solve climate change | Anote Tong. The Guardian. https://www.theguardian.com/world/commentisfree/2018/oct/10/while-myislandnation-sinks-australia-is-doing-nothing-to-solve-climate-change

Türk, V., \& Garlick, M. (2019). Addressing Displacement in the Context of Disasters and the Adverse Effects of Climate Change: Elements and Opportunities in the Global Compact on Refugees. International Journal of Refugee Law, 31(2/3), 389-399.

Uan, L. (2013, February). 'I-Kiribati want to migrate with dignity' | Climate Change. Retrieved March 21, 2020, from http://www.climate.gov.ki/2013/02/12/i-kiribati-want-to-migrate-with-dignity/

UNHCR. (2019). Co-Convenor's Summary: 2019 Global Refugee Forum. https://www.unhcr.org/events/conferences/5dfa70e24/summary-first-globalrefugeeforum-co-convenors.html 
Beyond burdens and climate refugees: a stocktake of international responsibility-sharing and South Pacific climate-induced migration

United Nations Economic and Social Commission for Asia and the Pacific. (2014). Climate Change and Migration Issues in the Pacific.

https://www.unescap.org/sites/default/files/Climate-Change-and-Migration-Issuesinthe-Pacific.pdf

United Nations Framework Convention on Climate Change. (1992).

United Nations High Commissioner for. (2019, December 16). Private sector steps up for refugees as Global Refugee Forum opens in Geneva. UNHCR. https://www.unhcr.org/news/press/2019/12/5df3ba964/private-sector-stepsrefugeesglobal-refugee-forum-opens-geneva.html

Urpelainen, J., \& Van de Graaf, T. (2018). United States non-cooperation and the Paris agreement. Climate Policy, 18(7), 839-851.

Voigt, C., \& Ferreira, F. (2016). "Dynamic Differentiation": The Principles of CBDR-RC, Progression and Highest Possible Ambition in the Paris Agreement—ProQuest. Transnational Environmental Law, 5(2), 285-303.

Wall, P. (2017). A New Link in the Chain: Could a Framework Convention for Refugee Responsibility Sharing Fulfil the Promise of the 1967 Protocol? International Journal of Refugee Law, 29(2), 201-237. https://doi.org/10.1093/ijrl/eex025

Walshe, R. A., Seng, D. C., Bumpus, A., \& Auffray, J. (2018). Perceptions of adaptation, resilience and climate knowledge in the Pacific: The cases of Samoa, Fiji and Vanuatu. International Journal of Climate Change Strategies and Management, 10(2), 303-322. https://doi.org/10.1108/IJCCSM-03-2017-0060

Walters, L. (2019, April 23). Climate migration a political tug of war. Newsroom. https://www.newsroom.co.nz/2019/04/23/548776?slug=pacific-climate-migrationapolitical-tug-of-war

Williams, M., \& Montes, M. F. (2016). Common but Differentiated Responsibilities: Which Way Forward? Development, 59(1), 114-120. https://doi.org/10.1057/s413010170097-6 
Beyond burdens and climate refugees: a stocktake of international responsibility-sharing and South Pacific climate-induced migration

World Meteorological Organization. (2020). WMO Statement on the State of the Global Climate in 2019 (WMO-No. 1248). World Meteorological Organization.

Yoon, P. (2020, January 8). Reflections on the First-Ever Global Refugee Forum. InterAction. https://www.interaction.org/blog/reflections-on-the-first-everglobalrefugee-forum/

Zenghelis, D., \& Averchenkova, A. (2014). Taming the beasts of "burden-sharing": An analysis of equitable mitigation actions and approaches to 2030 mitigation pledges'. Centre for Climate Change Economics and Policy, Grantham Research Institute on Climate Change.

Zhang, Y., \& Shi, H.-L. (2014). From burden-sharing to opportunity-sharing: Unlocking the climate negotiations. Climate Policy, 14(1), 63-81.

Zickgraf, C. (2019). Keeping People in Place: Political Factors of (Im)mobility and Climate Change. Social Sciences, 8(8), 228. https://doi.org/10.3390/socsci8080228 @ realDonaldTrump, Twitter, https://twitter.com/realDonaldTrump 